\title{
Global Relationships between Cropland Intensification and Summer Temperature Extremes over the Last 50 Years
}

\section{Citation}

Mueller, Nathaniel D., Andrew Rhines, Ethan E. Butler, Deepak K. Ray, Stefan Siebert, N. Michele Holbrook, and Peter Huybers. 2017. "Global Relationships between Cropland Intensification and Summer Temperature Extremes over the Last 50 Years." Journal Of Climate 30, no. 18: 7505-528.

\section{Permanent link}

http://nrs.harvard.edu/urn-3:HUL.InstRepos:41012277

\section{Terms of Use}

This article was downloaded from Harvard University's DASH repository, and is made available under the terms and conditions applicable to Open Access Policy Articles, as set forth at http:// nrs.harvard.edu/urn-3:HUL.InstRepos:dash.current.terms-of-use\#OAP

\section{Share Your Story}

The Harvard community has made this article openly available.

Please share how this access benefits you. Submit a story.

\section{Accessibility}




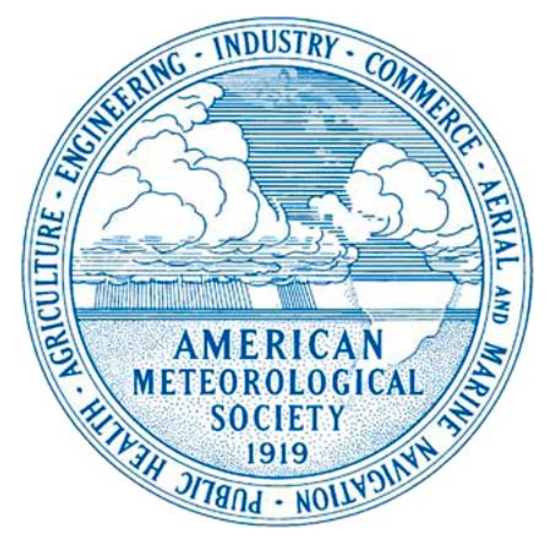

\section{AMERICAN METEOROLOGICAL SOCIETY}

Journal of Climate

\section{EARLY ONLINE RELEASE}

This is a preliminary PDF of the author-produced manuscript that has been peer-reviewed and accepted for publication. Since it is being posted so soon after acceptance, it has not yet been copyedited, formatted, or processed by AMS Publications. This preliminary version of the manuscript may be downloaded, distributed, and cited, but please be aware that there will be visual differences and possibly some content differences between this version and the final published version.

The DOI for this manuscript is doi: 10.1175/JCLI-D-17-0096.1

The final published version of this manuscript will replace the preliminary version at the above DOI once it is available.

If you would like to cite this EOR in a separate work, please use the following full citation:

Mueller, N., A. Rhines, E. Butler, D. Ray, S. Siebert, N. Holbrook, and P. Huybers, 2017: Global Relationships Between Cropland Intensification and Summer Temperature Extremes Over the Last 50 Years. J. Climate. doi:10.1175/JCLI-D17-0096.1, in press. 


\title{
Global Relationships Between Cropland Intensification and Summer
}

\author{
Temperature Extremes Over the Last 50 Years \\ Nathaniel D. Mueller* \\ Department of Earth System Science, University of California, Irvine, CA, USA \\ Andrew Rhines \\ Department of Atmospheric Sciences, University of Washington, Seattle, WA, USA \\ Ethan E. Butler \\ Department of Forest Resources, University of Minnesota, St. Paul, MN, USA \\ Institute on the Environment, University of Minnesota, St. Paul, MN, USA
}

Stefan Siebert

Institute of Crop Science and Resource Conservation, University of Bonn, Bonn, Germany

Department of Organismic and Evolutionary Biology, Harvard University, Cambridge, MA, USA

$$
\text { Peter Huybers }
$$

Department of Earth and Planetary Sciences, Harvard University, Cambridge, MA, USA 
${ }_{17}$ *Corresponding author address: Department of Earth System Science, University of California, 18 Irvine, Croul Hall, Irvine, CA, 92697, USA

${ }_{19}$ E-mail: nathan.mueller@uci.edu 
ABSTRACT 
Conversion of native ecosystems to cropland and the use of irrigation are considered dominant pathways through which agricultural land use change alters regional climate. Recent research proposes that increases in cropland productivity, or intensification, also influences climate through increasing evapotranspiration. Increases in evapotranspiration are expected to have the greatest temperature influence on extremely hot summer days with high vapor pressure deficits. Here we assess the generalizability and importance of such relationships by examining historical land use and climate trends in seven regions across the globe, each containing a major temperate or subtropical cropping area. Trends in summer high temperature extremes are sequentially compared against trends in cropland area, area equipped for irrigation, precipitation, and summer cropping intensity. Trends in temperature extremes are estimated using quantile regression of weather station observations, and land use data are from agricultural inventories and remote sensing. Intensification is the best predictor of trends in extreme temperatures amongst the factors that we consider, and is generally associated with trends that are $0.2-0.4^{\circ} \mathrm{C}$ per decade cooler than in adjacent regions. Neither cropland area nor precipitation trends are systematically associated with extreme temperature trends across regions, though high temperatures are suppressed over those portions of Central North America and East Asia experiencing growth in irrigation. Both the temperature trends associated with intensification and increased irrigation can be understood as a consequence of increased latent cooling. These results underscore that the weather experienced by crops is not entirely external, but also depends on agricultural practices. 


\section{Introduction}

Climate is a central determinant of crop distribution and productivity, yet climate itself can be influenced by agricultural land use and land cover via biophysical changes to surface albedo, rates of evapotranspiration, and surface roughness (Foley et al. 2003; Brovkin et al. 2004; Feddema et al. 2005; Diffenbaugh 2009; Pielke Sr. et al. 2011). Conversion of native ecosystems to cropland and the use of irrigation have long been considered dominant pathways through which agricultural land use alters regional temperatures. In the United States, cropland expansion altered albedo and evapotranspiration patterns and is thought to have cooled growing season temperatures (Bonan 1999, 2001; Oleson et al. 2004; Twine et al. 2004; Diffenbaugh 2009). Irrigation increases evapotranspiration and decreases temperatures, a relationship that has been documented in the US Great Plains (Adegoke et al. 2003; Mahmood et al. 2006; Bonfils and Lobell 2007; Lobell et al. 2008; Harding and Snyder 2012; Lu et al. 2015), the Central Valley of California (Bonfils and Lobell 2007), Sudan (Alter et al. 2015b), and Asia (Bonfils and Lobell 2007). More recently, other changes to cropland management have been shown to alter climate. Multiple-cropping practices influence the seasonality of evapotranspiration in the North China Plain (Jeong et al. 2014) and the Brazilian Cerrado (Spera et al. 2016), and are associated with higher temperatures during the inter-cropping period (Jeong et al. 2014). No-till practices can increase post-harvest albedo, and model simulations suggest that increased adoption of no-till on winter-season crops in Western Europe could substantially cool summer extreme temperatures (Davin et al. 2014).

Another recently proposed pathway by which agricultural land use can influence climate is through the intensification of crop production on existing croplands and an associated increase in evapotranspiration. Mueller et al. (2016) demonstrated century-long cooling trends in the US Midwest that were proportional to trends in intensification documented in crop survey data, where 
intensification was defined as a positive trend in local crop biomass production. Cooling was observed for both irrigated and rainfed croplands that have undergone intensification, but with the important caveat that temperatures revert to historically high magnitudes during drought conditions in rainfed regions. These results are broadly consistent with studies of climatic trends for cropland in the Canadian Prairies (Gameda et al. 2007; Betts et al. 2013), where it was found that summer maximum temperatures decreased over the past several decades. Gameda et al. (2007) and Betts et al. (2013) attributed this pattern to greater landscape productivity and evapotranspiration due to declines in summer fallow practices, although the US Midwest findings (Mueller et al. 2016) suggest that increased productivity on planted areas also contributed to changes in evapotranspiration across the Canadian Prairies.

In addition to observational evidence from historical data, the expectation that higher productivity landscapes exhibit greater evapotranspiration accords with a number of field-scale studies. Vegetation productivity is tightly coupled to rates of evapotranspiration, and vegetation mediates the relationship between surface energy fluxes and soil moisture (Williams and Torn 2015). High-nitrogen application has been shown to result in both a larger magnitude (Jones et al. 1986; Rudnick and Irmak 2014) and duration (Rudnick and Irmak 2014) of peak evapotranspiration in maize. Nitrogen stress can otherwise be an important control on evapotranspiration through inhibiting leaf area, stomatal conductance, and root development (Jones et al. 1986; Chapin III et al. 1988), but is largely alleviated in high-intensity cropping systems. Some crops are now managed at much greater planting densities (Duvick 2005), a change that can also lead to greater rates of evapotranspiration (Jiang et al. 2014). Adoption of conservation tillage practices, common in the US (Horowitz et al. 2010), suppresses soil evaporation early in the season and thus can conserve water for transpiration (Gallaher 1977). Changes in cultivars may also influence transpiration char- 
acteristics, as more recent cultivars tend to have higher rates of stomatal conductance and lower canopy temperatures (Fischer et al. 1998; Barker et al. 2005; Roche 2015).

Given that the pace of cropland expansion has been relatively slow since 1950 (Ramankutty and Foley 1999), and that widespread increases in crop productivity occurred during this time period due to the adoption of "Green Revolution" technologies and management practices (Tilman et al. 2002), intensification of existing croplands may now be a dominant mechanism through which agricultural practices change regional climate. However, this relationship has only been documented in the the US Midwest (Mueller et al. 2016), an area that exhibits the most pronounced peak summer vegetation growth of anywhere on the planet (Guanter et al. 2014; Mueller et al. 2016). It is unclear whether more modest increases in crop productivity would significantly influence high temperature trends elsewhere, and variability in cropping practices, soils, and atmospheric conditions also raise questions about the geographic generalizability of the US Midwest intensification-cooling relationship. Examination of other regions provides an opportunity to test whether intensification is systematically related to a suppression of high temperatures.

Here we examine the relationship between extremely hot maximum temperatures and summer cropland intensification, as well as the relative importance of intensification alongside changes in cropland area, irrigation growth, and precipitation, by analyzing land use and extreme temperature trends for seven regions across the globe (Figure 1). The management (Mueller et al. 2012; Mueller and Binder 2015; Siebert et al. 2015), productivity (Monfreda et al. 2008; Ray et al. 2012, 2013), and phenology (Sacks et al. 2010; Guanter et al. 2014) of crops varies widely across regions, providing a useful series of case studies to examine land-atmosphere connections with observational data. The analysis is restricted to subtropical and temperate regions due to greater availability of high-quality weather station records and the presence of well-defined seasonality in extreme temperatures and evaporative demand. We focus on summer as the season when evap- 
orative demand is greatest and when temperature extremes generally have the greatest societal consequences, although crop damages from extreme heat will depend upon the specific timing of the exposure relative to sensitive periods of crop development (Gourdji et al. 2013; Butler and Huybers 2015). Consistent with Mueller et al. (2016), we examine the $95^{\text {th }}$ percentile of summer daily maximum temperatures using quantile regression. Hot extremes exhibit unique trends relative to lower percentiles of the temperature distribution (McKinnon et al. 2016; Mueller et al. 2016), and are particularly sensitive to changes in evapotranspiration (Seneviratne et al. 2010; Mueller and Seneviratne 2012; Huybers et al. 2014; Mueller et al. 2016).

\section{Data and Methods}

The ability to document global-scale relationships between climatic trends and changes to summer cropping intensity, irrigation, and cropland area is only recently possible due to the release of several global historical land use datasets used in coordination with weather station and satellite observations. Below we detail our geographic areas of interest, the analysis of land use trends, and the analysis of temperature and precipitation trends.

\section{a. Regions and major cropping systems}

Relationships between agricultural land use and climate trends are examined across seven broad regions (orange lines in Figure 1). We also identify grid cells comprising an intensified major cropping area in each region; these grid cells are utilized solely to characterize local crop phenology in a series of descriptive plots. To define these grid cells, we first delineate the most important continuous cropland regions (latitude and longitude boundaries are shown in the dashed lines in Figure 1). Grid cells within these boundaries are then classified as a "major cropping area" if they 
contain greater than 50\% cropland according to a circa 2000 dataset (Ramankutty et al. 2008) and exhibit positive trends in our summer cropping intensity index, defined below.

\section{b. Cropland area trends}

Historical cropland area is estimated from agricultural census records in combination with land cover classifications from remote sensing Ramankutty and Foley (1999). The dataset has been recently updated (N. Ramankutty, personal communication, February 2014) and is now available at half-degree resolution between 1961-2007. Trends are fit over this available interval using simple linear regression (Figure 2a).

\section{c. Irrigated area trends}

Data on area equipped for irrigation have been compiled by Siebert et al. (2015) into a gridded dataset at 5 arc-minute resolution covering the years 1900-2005, with maps available every ten years from 1900-1980 and every five years after 1980. This dataset is based on agricultural census information and detailed local land use maps. We utilize the AEI-EARTHSTAT-IR version of the dataset that is constructed using the update to Ramankutty and Foley (1999) cropland areas. Trends are fit to grid cell area equipped for irrigation (AEI) values for 1961-2005 (Figure 2b), where values for 1961 are calculated by linearly interpolating between 1960 and 1970 values in each grid cell. We fit trends at the native resolution of the irrigation dataset and all subsequent gridded data, then upscale by averaging to half-degree resolution so that all datasets are on a common grid. 


\section{d. Summer cropping intensity trends}

To evaluate trends in summer cropping intensity (where a positive trend is considered "cropland intensification"), we develop an index of Summer Cropping Intensity (SCI) that quantifies yearly summer crop biomass production across the landscape in units of grams of Carbon per square meter produced over the summer growing season, i.e. $\mathrm{g} \mathrm{C} \mathrm{m}^{-2}$ summer $^{-1}$. Yearly crop biomass production can be calculated from historical crop-specific harvested area and yield data, along with parameters that relate yields to total crop biomass. Unfortunately, these datasets do not also detail the seasonality of crop growth, a crucial consideration since changes to crop evapotranspiration characteristics only plausibly influence summer temperature extremes when crop growth occurs during the summer. Many temperate areas grow some crops during a "winter season", when the crop is planted in the autumn and is harvested in the late spring or early summer, so a summer growing season cannot be assumed. In earlier work focused on the US, Mueller et al. (2016) were able to isolate statistics for summer crop types, but this is not possible with the global crop datasets that we employ. To incorporate the seasonality of crop growth, we use remote sensing data to calculate the fraction of vegetation growth occurring during summer ("vegetation summer fraction", or VEGsf). We then utilize VEGsf as a fractional weight on crop biomass to convert annual cropping intensity to SCI. The crop datasets and calculations are described in greater detail below.

Calculating annual crop biomass production: To obtain trends in crop biomass production for six major crops, we first calculate the net primary productivity per harvested area (NPPha, in units of $\mathrm{g} \mathrm{C} \mathrm{m}^{-2} \mathrm{yr}^{-1}$ ) of each crop from data on the yield ( $\mathrm{Y}$, converted to units of $\mathrm{g} / \mathrm{m}^{2}$ ) of harvested crop products, as well as the dry fraction of the harvested product (DF, g/g), the carbon content (C, 
$\mathrm{gC} / \mathrm{g}$ ), the harvest index (HI, g/g), and the aboveground fraction (AF, g/g). Following Monfreda et al. (2008),

$$
\mathrm{NPPha}_{c, i, y}=\frac{\mathrm{Y}_{c, i, y} \mathrm{DF}_{c} \mathrm{C}}{\mathrm{HI}_{c, y} \mathrm{AF}_{c}} \text {. }
$$

where $c$ is the crop type, $y$ is the year, and $i$ represents the index of each grid cell. We use gridded, crop-specific yield data spanning the years 1961-2008. Yield data for maize (grain, not silage), wheat, soybean, and rice are from Ray et al. (2012), and are generally resolved sub-nationally for major agricultural countries, although the temporal frequency of source data depends upon availability. Yield data for barley and rapeseed are from Monfreda et al. (2008), and are resolved sub-nationally for the year 2000. To obtain a historical time series, we scale these base maps to match the national-level average yield data from the United Nations Food and Agricultural Organization (FAO 2016), while preserving sub-national spatial heterogeneity in yields from 2000. Values for DF, C, AF, and modern HI are directly from Monfreda et al. (2008). The harvest index of some crops has changed as a result of crop breeding, and historical values are reported in Table 1. In lieu of detailed data about the temporal evolution of HI, we assume a linear scaling between historical and modern values from 1910 to 1980, with modern values used for 1980 and all subsequent years. The use of historically varying HI values decreases the calculated intensification trend and works in opposition to the yield trends, but the latter are much larger and dominate the intensification trends. Our results are not sensitive to the use of historically varying harvest indices. Harvested area is relevant for considering the extent to which cropland evapotranspiration characteristics influence temperature. A large increase in evapotranspiration across a small field would, obviously, have limited influence on regional air temperatures. Thus, we multiply NPPha by the harvested area for each crop $\left(\mathrm{HA}_{c}\right.$, in units of $\left.\mathrm{m}^{2}\right)$ relative to the total area within each grid cell $\left(\mathrm{TA}, \mathrm{m}^{2}\right)$, giving an area-normalized net primary productivity metric (NPPan), 


$$
\mathrm{NPPan}_{i, y}=\sum_{c=1}^{6} \frac{\mathrm{NPPha}_{c, i, y} \mathrm{HA}_{c, i, y}}{\mathrm{TA}_{i}} .
$$

Harvested area data for our six crops are from the same sources (Monfreda et al. 2008; Ray et al. 2012; FAO 2016) as the yield data. The units for NPPan remain $\mathrm{g} \mathrm{C} \mathrm{m}^{-2} \mathrm{yr}^{-1}$, although the $\mathrm{m}^{-2}$ is now relative to grid cell area and not harvested area. Trends in NPPan are fit for 1961-2008 (Figure 3a), and provide a useful measure of cropland intensification for our six crops. However, as previously mentioned, these estimates do not indicate whether that intensification would have occurred during a summer growing season, or at other portions of the year.

Weighting by the vegetation summer fraction to calculate SCI: The GOME-2 satellite record of sun-induced chlorophyll fluorescence (SIF) (Joiner et al. 2013) is our preferred source of data for calculating VEGsf. These data are available at monthly, 0.5 degree resolution. Chlorophyll fluorescence has previously been shown to exhibit closer correspondence with cropland gross primary productivity (GPP) from eddy flux towers than reflectance-based indices (Guanter et al. 2014). However, the relatively coarse resolution implies that the fluorescence data captures photosynthesis from both native and managed vegetation. This limitation is more pronounced for heterogeneous landscapes (e.g. Western Europe) as opposed to those that are comparatively dominated by crops (e.g. the North American Corn Belt).

Using the SIF data, we calculate the fraction of vegetation growth occurring during the summer months (VEGsf). Assuming a simple linear scaling between SIF and GPP, the units for VEGsf are (g/summer)/(g/year). Summer is defined as June-August (JJA) in the Northern Hemisphere and December-February (DJF) in the Southern Hemisphere. Thus, for the Northern Hemisphere, 


$$
\text { VEGsf }_{i}=\frac{\sum_{m=6}^{8} \operatorname{SIF}_{m, i}}{\sum_{m=1}^{12} \operatorname{SIF}_{m, i}},
$$

where $m$ is the month. Any negative SIF values, which do arise due to measurement errors, are set to zero prior to calculating VEGsf. We use the average summer fraction during the recent years of 2007-2012 (Figure 3b), and we test whether this fraction has varied over time using NDVI data as described below. Summer fraction is not calculated for areas with insufficient signal, here specified as monthly average fluorescence less than $1 / 12 \mathrm{~mW} \mathrm{~m}^{-2} \mathrm{sr}^{-1} \mathrm{~nm}^{-1}$ (these areas are shown as light gray in Figure 3b).

Our final summer cropping intensity index, SCI, is constructed by using VEGsf to weight NPPan, and is calculated for all locations in the extratropics,

$$
\mathrm{SCI}_{i, y}=\mathrm{NPPan}_{i, y} \mathrm{VEGsf}_{i} .
$$

Trends in the SCI index (Figure 3c) retain the prominent NPPan trends in summer cropping areas (e.g. the US Corn Belt and the Canadian Prairies) while NPPan trends in predominantly winter-cropping areas are down-weighted (e.g. in portions of the US Southern Great Plains and Southern Australia).

VEGsf sensitivity analysis: An alternate source of data for calculating VEGsf is the Global Inventory Monitoring and Modeling System (GIMMS) Normalized Difference Vegetation Index (NDVI) record generated from the Advanced Very High Resolution Radiometer (AVHRR) (Tucker 2014). These data are available bi-monthly at 5 arc-minute resolution and span 1982-2013. Despite the aforementioned drawbacks of reflectance-based indices, this NDVI data permits an alternate estimation of SCI for comparison against our standard SIF approach. To permit for direct comparison against the SIF estimate, NDVI seasonality is computed over the 2007-2012 interval. 
SCI is calculated at the 5 arc-minute resolution permitted by the NDVI data, and then averaged to 0.5 degree resolution. The long temporal record also allows us to examine the extent to which VEGsf has changed over time, a topic we return to in Section $3 \mathrm{~h}$.

\section{e. Crop calendar data}

Additional information about the seasonal cycle of crop development can be determined from global crop calendar data, and we use these data as contextual information for interpreting our findings. Average regional planting and harvest dates by crop type, as well as typical ranges around those means, are taken from the Sacks et al. (2010) database. These data do not include information about trends in planting and harvest dates as influenced by management practices and climate trends (e.g. Kucharik 2006). Spatial averages across major cropping regions are calculated for each crop type, where averages are weighted according to grid cell crop harvested areas (Monfreda et al. 2008). Planting and harvest dates for summer rapeseed in Canada are from USDA (1994), because Sacks et al. (2010) only contains data on winter rapeseed. We also determine crop harvested areas (Monfreda et al. 2008) circa 2000 as fractions of the total land area within each major cropping system. These values are shown in planting and harvest date figures to indicate the relative importance of various crops in each region. Planting and harvest data are presented alongside seasonal cycles of SIF for further context on local phenology in each major cropping area.

\section{f. Climate trends}

Weather station data is from the Global Historical Climatology Network - Daily dataset (GHCND) (Menne et al. 2012). Observations with negative quality flags are removed. In the interest of achieving a relatively complete geographic sample, we include any station where a 
minimum of $60 \%$ of days (after quality filtering) report values of maximum temperature from 1961-2014. All regions have average coverage considerably above this baseline, as shown in Table 2.

Quantile regression (Koenker and Bassett 1978) is utilized to assess trends in temperature extremes, and we focus on trends in the $95^{\text {th }}$ percentile of daily maximum temperature observations during the summer months of June-August in the Northern Hemisphere and December-February in the Southern Hemisphere (Figure 4). Temperature data were originally recorded in Fahrenheit and Celsius at different levels of precision, and then were rounded to standard increments of $0.1^{\circ} \mathrm{C}$ for inclusion in GHCND. This heterogeneity poses problems for understanding trends in extreme temperatures, since quantile regression assumes continuously distributed data and is biased by rounding artifacts. We correct for the effects of rounding by adding an appropriate amount of jitter to each observation to approximately correct each temperature record to its unrounded distribution, where jitter amplitude is determined from the results of a precision-decoding algorithm (Rhines et al. 2015).

Although daily temperature observations are the most suitable record for directly examining large-scale changes in extreme temperatures, station data is subject to a number of uncertainties. Station moves, changes in the time of observation, and shifts in equipment can all influence temperature observations (Quayle et al. 1991; Pielke Sr et al. 2007; Menne and Williams 2010). Examination of trends in temperature extremes in North America, using the same GHCND data and quantile regression approach, shows consistency between neighboring stations as well as between stations and reanalyses (Rhines et al. 2016), indicating that the influence of inhomogeneities in the daily temperature data are minor relative to trends in extreme temperature. Furthermore, pairwise comparison of summer temperature trends calculated from GHCND and from nearby hourly stations sampled using a consistent time of day window indicate that time-of-observation biases are 
small compared with typical magnitudes of summer temperature trends (McKinnon et al. 2016). Within the US, the widespread change in thermometers during the 1980s is thought to have introduced a cool bias to maximum temperatures of around $0.4^{\circ} \mathrm{C}$ (Quayle et al. 1991). We suggest that these inhomogeneities and uncertainties in the data, while important for understanding the absolute magnitude of temperature trends, will have less influence on our identification of land use effects, given our focus on spatial differences in temperature trends. Moreover, the extent to which results are consistent between countries with different weather station networks serves as an important check on the robustness of our results.

Trends in precipitation are analyzed for the same subset of stations used to examine temperature trends. Precipitation can influence extreme temperatures through the influence of soil moisture availability on evapotranspiration (Mueller and Seneviratne 2012), and can also be affected by land use change (Pielke Sr. et al. 2007; DeAngelis et al. 2010; Harding and Snyder 2012; Alter et al. 2015a,b; Mueller et al. 2016). The relationship between precipitation and evapotranspiration is modulated by the ability of vegetation to access stored soil moisture in the root zone, which generally acts to suppress the impacts of precipitation anomalies on evapotranspiration (Betts et al. 2014). Average precipitation per day is calculated by season and year, and from these averages seasonal total precipitation is estimated for every year where at least $80 \%$ of daily observations are present. Trends are then calculated for seasonal total precipitation using simple linear regression for every station where at least $80 \%$ of the seasonal totals are present (Figure 2c).

The land area most closely associated with each weather station is calculated using spherical Voronoi polygons (Renka 1997). For coastal stations that fall just outside of our coastal boundaries, a minimum area of 1 hectare is associated with the station. Station area is used to calculate the widths of boxes in our boxplot figures, and to scale the dot sizes associated with weather station locations on figures showing temperature and precipitation trends. 


\section{g. Statistical analysis}

A bootstrap test is utilized to assess the significance of $95^{\text {th }}$ percentile temperature trends for weather stations experiencing a given shift in precipitation or land use relative to stations experiencing little change in that explanatory variable. Groupings of stations by land use and precipitation are shown in subsequent boxplots for each region. The test accounts for spatial autocorrelation by resampling all station observations identically, and accounts for temporal autocorrelation by resampling three-month seasonal blocks. For each bootstrap replicate (1000x), $95^{\text {th }}$ percentile temperature trends are fit to the resampled data at each station using quantile regression. We then take the difference in the mean trend of stations experiencing a given shift in land use or precipitation and the mean trend of stations experiencing no change in that explanatory variable. This procedure generates a distribution of mean differences that is compared with zero to determine a two-sided p-value. The test is similar to the approach taken in Mueller et al. (2016), although that analysis was with respect to whether temperature trends grouped by a given explanatory variable were significantly different than zero, whereas here we evaluate if temperature trends are significantly different from adjacent areas that have little change in the explanatory variable.

\section{h. Case study}

An example illustrating the temporal resolution of the land use and climate data employed in this study is presented in Figure 5 for Redwood County, Minnesota, USA. Maize and soybean are the dominant crops in the area, and both crops exhibit increasing yields since 1960 (Figure 5a,b). Increases in maize and soybean harvested area (Figure 5a) have been at the expense of other crops, with total cropland area remaining roughly constant (Figure 5e). Cropland area represents all land devoted to crops and therefore tends to be more stable than harvested areas of individual crops, which can be affected by changing market conditions and weather-induced crop failure 
(for example, note the drop in maize harvested area during the flood of 1993). Area equipped for irrigation is negligible (Figure 5e). Summer precipitation shows substantial inter-annual variability and a modest long-term trend of $7 \mathrm{~mm}$ per decade (Figure 5e, regression line not shown).

Yield and harvested area data are combined according to Eqs. 1, 2 to calculate NPPan (Figure 5d), and linearly scaled into SCI using SIF-determined summer fraction of photosynthesis (VEGsf) according to Eqs. 3, 4. The approximately linear increase in SCI over time reflects increases in yield and greater land devoted to high-yielding maize and soybean crops (Figure 5c). Variations in crop types, crop productivity, planting schedules, or weather could all cause the summer fraction of SIF to vary with year. Although disaggregating the reasons for variations in satellite-based estimates of VEGsf is beyond the scope of this paper, it is possible to examine the summer fraction as a function of year back to 2007 using SIF and 1981 using NDVI. Both products show interannual variability but neither exhibit strong trends. VEGsf calculated using SIF is systematically higher than when calculated using NDVI, an expected pattern since SIF tracks GPP more closely than NDVI (Guanter et al. 2014).

The distribution of summer temperatures is indicated in Figure 5f, where the size of dots indicate the frequency of temperature observations during the summer months, binned to the nearest $0.5^{\circ} \mathrm{C}$ for legibility. Quantile regression of the $95^{\text {th }}$ percentile temperature shows a decreasing temperature trend of $-0.3^{\circ} \mathrm{C} /$ decade. A block-bootstrap of the daily temperature data is used to assess significance of the temporal trend. For each bootstrap replicate, years are sampled with replacement, and all summer temperature observations are used for every year sampled. Quantile regression trends are fit to the sampled data for 1000 bootstrap replicates. The distribution of $95^{\text {th }}$ percentile temperature trends from the bootstrap demonstrates that this trend significantly differs from zero at 95\% confidence (Figure $5 \mathrm{~g}$ ). Note that although this calculation of significance applies to the temporal trend for this individual station, our calculation of significance related to land 
use and precipitation trends depends upon relative temperature trends between weather stations grouped according to various explanatory variables.

Four different predictor variables are considered candidates for explaining the observed trends in $95^{\text {th }}$ percentile temperatures: total cropland area, area equipped for irrigation, precipitation, and SCI. We consider the explanatory power of each of these variables by examining the regionwide associations between temperature trends and trends in each predictor variable. In Redwood County, we see that each variable other than SCI displays minor trends since 1960. When examining region-wide associations between the predictor variables and temperature trends, the Redwood County weather station would therefore be included in the control group of stations (see boxplots below) for both trends in cropland area and trends in area equipped for irrigation. For the precipitation analysis, the station would be grouped with other stations with modest positive trends. $\mathrm{SCI}$ is the only predictor variable with a strong positive trend that co-occurs with the significant cooling in summer $95^{\text {th }}$ percentile temperatures.

\section{Results and Discussion}

Trends in $95^{\text {th }}$ percentile summer maximum temperatures are systematically cooler over intensified croplands relative to neighboring areas. This relationship holds in every region where summer cropping is the dominant land use, including for Central North America, Northern North America, Northern East Asia, Southern East Asia, and Southern South America. Median trends in $95^{\text {th }}$ percentile maximum temperatures are $0.2-0.4^{\circ} \mathrm{C}$ per decade in intensifying areas compared to adjacent areas not experiencing intensification. No relationship is found in Western Europe and Southern Australia, areas where winter cropping dominates. Consistent with earlier work (Mueller et al. 2016), cooling is found in rainfed areas, such as the Canadian Prairies and much of the North American Corn Belt, as well as in irrigated areas. Substantial irrigation growth has 
occurred in East Asia, helping facilitate increases in cropland productivity. Therefore, both irrigated area trends and summer intensification trends are related to cooler temperature extremes in these areas. Changes in cropland area and precipitation are generally weak predictors of trends in extreme temperatures.

In each region discussed below, the relationship between weather station $95^{\text {th }}$ percentile temperature trends and local trends in our candidate predictor variables is described, discussed in the context of the literature, and presented visually using a series of boxplots. Candidate predictor variables are the local trends in cropland area, area equipped for irrigation, summer cropping intensity, and precipitation (from the same weather station). All trends in predictor variables are calculated using simple linear regression (Section 2b-d,f). In each plot, weather stations are evenly binned into subsets of stations according to local trends in the predictor variables. Subsetting allows us to examine how temperature trends vary with trends in the predictors in a way that is independent of functional form, and provides the basis for the aforementioned bootstrap test. Each box and whiskers displays the full range of $95^{\text {th }}$ percentile temperature trends for a given subset of weather stations, with asterisks indicating the significance of the temperature trends.

\section{a. Central North America}

Cropland intensification is strongly associated with cooling in the Central North America region (Figure 6), which covers most of the continental United States and southeast Canada. These results are consistent with earlier results identifying an association between intensification and cooling from 1910-2014 using USDA crop survey data of twelve summer crop types (Mueller et al. 2016). Trends in $95^{\text {th }}$ percentile temperatures (Figure 4) tend to show cooling or absence of warming over intensified cropland areas, while much of the rest of the region shows warming of around $0.1^{\circ} \mathrm{C}$ per decade. 
The dominant crops within the North American Corn Belt are maize (accounting for 25\% of total area) and soybeans (24\%) and their growth is centered on summer months (Figure 7). Average values of summer SIF across the world's mid-latitudes are around $0.8 \mathrm{~mW} / \mathrm{m}^{2} / \mathrm{sr} / \mathrm{nm}$, but in Central North America they peak in July at values exceeding $3 \mathrm{~mW} / \mathrm{m}^{2} / \mathrm{sr} / \mathrm{nm}$, the largest values found for any spatially extensive region on the globe (Guanter et al. 2014; Mueller et al. 2016). The anomalously high productivity of the region is reflected values of SCI that are higher than any other major cropping area (Table 3). We infer that achieving these high rates of photosynthesis during the summer season has led to corresponding increases in evapotranspiration. This inference is supported by estimates of a positive evapotranspiration trend over the Mississippi basin (Milly and Dunne 2001) and is consistent with trends towards greater specific and relative humidity during summer in regions of intensified crop growth (Sandstrom et al. 2004; Brown and DeGaetano 2013). Further, we note that climate models from phase 5 of the Coupled Model Intercomparison Project (CMIP5) simulate temperature increases over the central US in response to historical forcings (Kumar et al. 2013), further emphasizing the importance of mechanisms not included in the models to explain historical temperature trends.

Extreme temperatures since 1961 have cooled most strongly over the western Corn Belt, an area of substantial land use change and expanding commodity crop production (Lark et al. 2015). The stronger cooling over this area may arise from more influential land use transitions or from the gradual reduction in aerosol forcing over eastern North America. The cooling influence of aerosols on temperatures is thought to have peaked during the 1970s-1990s, therefore reductions in forcing would contribute to a warming trend that may counteract the influence from intensification (Leibensperger et al. 2012a,b). Since the climate of the western Corn Belt was never as strongly influenced by aerosols, this may explain the stronger cooling observed in this area. 
Increasing area equipped for irrigation is found across the Great Plains and in rice-growing areas adjacent to the Mississippi River. Those locations where area equipped for irrigation increased $2.5-3.5 \%$ of grid cell area per decade show significant cooling of $95^{\text {th }}$ percentile summer temperatures $(\mathrm{p}<0.05)$ relative to regions with near-constant irrigated area (Figure $6 \mathrm{~b})$, and become yet more significant for decadal trends greater than $3.5 \%$. However, the amount of cooling area associated with increasing irrigation is only $14 \%$ of that associated with intensification, emphasizing that increases in vegetation productivity influence evapotranspiration characteristics, whether in irrigated or rainfed areas. Area calculations are performed using Voronoi polygons associated with each weather station exhibiting negative $95^{\text {th }}$ percentile temperature trends and associated with either at least $2.5 \%$ increases in irrigated area per decade (Figure 6b) or intensification trends of at least $0.5 \mathrm{~g} \mathrm{C} \mathrm{m}^{-2}$ summer $^{-2}$ (Figure 6d).

Trends in cropland area are inconsistently related to $95^{\text {th }}$ percentile temperature trends (Figure 6a). The appearance of significant cooling in relation to $2 \%$ per decade growth in cropland area may reflect greater evapotranspiration from cropland expansion, but also may result from the fact that we test candidate mechanisms in isolation. The presence of extreme temperature trends primarily driven by changes in irrigation and intensification makes it more likely that a random subsetting of the region can contain temperature trends that are larger than that of the control group. In future work, a multi-factor panel analysis would likely prove a better indicator of exact significance.

Weather stations with decreased precipitation have slightly higher extreme temperature trends than other stations, which would be consistent with the effects of lower soil moisture, decreased evapotranspiration, and greater sensible heating from the land surface (Figure 6c). However, the warming relationship is not significant for all subsets of stations with decreasing precipitation, and stations with increasing precipitation do not exhibit significant cooling. In contrast, Mueller et al. 
(2016) found a significant relationship between precipitation increases and cooler temperatures in the Midwest United States in their study of trends over the last century. They noted that such trends may be partly due to cropland intensification (Mueller et al. 2016) or irrigation growth across the Great Plains (DeAngelis et al. 2010; Harding and Snyder 2012; Alter et al. 2015a), since precipitation in the region is strongly influenced by rates of evapotranspiration (Betts 2004). The present analysis focused on trends since 1961 shows some areas of increasing precipitation in the region (Figure 2c), but no significant relationship between cooling and elevated precipitation.

\section{b. Northern North America}

Northern North America also shows cooling of $95^{\text {th }}$ percentile temperatures associated with cropland intensification (Figure 8). Irrigation growth has been minimal and shows no strong relationship with the pattern of temperature trends. Crop phenology in the Canadian Prairies is strongly summer seasonal but with a shorter growing season than in the Corn Belt.

Our findings align with earlier studies that identified a cooling of maximum temperatures and an increase in relative humidity during the period of peak crop growth in the Canadian Prairies (Gameda et al. 2007; Betts et al. 2013, 2016). This cooling was attributed to greater landscape evapotranspiration from declining cropland area left fallow during summer (Betts et al. 2013). Increased productivity on planted areas and declining summer fallow will both influence SCI respectively via changes to crop yields and harvested areas. The SCI trend in heavily cropped areas is $1.4 \mathrm{~g} \mathrm{C} \mathrm{m}^{-2}$ summer $^{-2}$ (Figure 2a). To distinguish harvested area and yield contributions to this trend, we re-calculate SCI holding each fixed (Figure 9). SCI trends from harvested area variations alone give a trend of $0.5 \mathrm{~g} \mathrm{C} \mathrm{m}^{-2}$ summer $^{-2}$. Conversely, SCI trends are $0.9 \mathrm{~g} \mathrm{C} \mathrm{m}^{-2}$ summer $^{-2}$ when only yields are allowed to vary. 
Insomuch as summer cooling is linearly proportional to SCI trends, which is far from clear but appears the simplest assumption, increasing productivity on planted areas (determined from the yield trends) is the dominant influence on cooling. However, we note that we find greater increases in SCI from changing harvested area in Alberta and Manitoba than in Saskatchewan, despite inventory data showing the greatest declines in fallow for Saskatchewan (Betts et al. 2013). This discrepancy may result from expansion of harvested area unrelated to declining summer fallow, crop types not included in our analysis, or local-scale changes that we do not resolve in our historical crop data. We are particularly limited in resolving spatial patterns of change for barley and rapeseed, since our area and yield time series are generated by perturbing circa 2000 maps with national-level data. A more complete analysis of influences on temperature would be possible by utilizing higher-resolution data on agricultural practices and by running regional climate simulations with fallow and productivity scenarios.

Gameda et al. (2007) and Betts et al. (2013) found increases in precipitation associated with elevated evapotranspiration during peak crop growth, indicating greater precipitation recycling and increased potential for deep convection triggered by land management shifts (Raddatz 1998). We also find positive precipitation trends over the Canadian Prairies (Figure 2c), lending support to this notion. However, the associations between $95^{\text {th }}$ percentile temperature trends and precipitation trends over the whole Northern North America region are more ambiguous. Areas with greater precipitation do not systematically show significantly cooler temperatures. However, most stations experiencing drying trends do have significantly elevated warming trends relative to the control group, consistent with decreases in evapotranspiration and increases in sensible heating. Greater temperature sensitivity to decreases in precipitation than to increases in precipitation is consistent with the results of Betts et al. (2017) for the Canadian Prairies, where it was demonstrated that 
the diurnal temperature range in the region exhibits greater coupling with precipitation anomalies during dry conditions than during wet conditions.

\section{c. Western Europe}

Intensification is not associated with cooling in Western Europe (Figure 10). The $95^{\text {th }}$ percentile temperature trends since 1961 show strong warming averaging $0.4^{\circ} \mathrm{C}$ per decade, and have insignificant relationships with cropland area, irrigation, and SCI trends. Temperature trends appear to decline with increasing precipitation trends, but this relationship is insignificant and weak compared to the predictor relationships found elsewhere.

These negative findings appear to result from the dominance of winter cropping and the heterogeneity of the landscape. SIF peaks during May when the growing season for barley, rapeseed, and winter wheat varieties all coincide. Of the crops examined, only maize has a long summer season where peak transpiration and peak temperatures would align. Grain maize only covers $3 \%$ of the landscape within the heavily cropped areas of Southern England and Northwest France. Silage maize for fodder is not included in our dataset, but judging from disaggregated maize area for France, including both would still only double this percentage (FAO 2016). For comparison, summer maize and soybean account for $49 \%$ of the total land area in the Central North American Corn Belt (Figure 6).

Moderate SIF values persist throughout the summer and give higher VEGsf values in Western Europe compared with more homogenous winter cropping areas such as Kansas and Southwest Australia (Figure 3b, Table 3). The resolution of the SIF input to VEGsf makes it difficult to separate this heterogeneous landscape into cropland and natural vegetation, leading to VEGsf values that are likely higher than would be observed on croplands alone. 
The general warming in Western Europe is therefore consistent with our hypothesis that intensification of summer crop production is associated with cooling. Given the low extent of summer cropping, the large majority of croplands are mature or harvested by late summer. The dominance of winter cropping systems affords the possibility of mitigating extremely hot temperatures by transitioning to no-till systems, which have increased summer surface albedo relative to tilled soil (Davin et al. 2014).

\section{d. Northern East Asia}

Intensification of summer crops coincides with suppressed extreme temperature trends in the Northern East Asia region, which encompasses northern China, Mongolia, Hokkaido (Japan), and eastern Russia, with a southern boundary of $40^{\circ} \mathrm{N}$, or roughly the latitude of Beijing. The major cropping area within this region is Northeast China, where summer cropping of maize, soybeans, and rice dominate the landscape. Warming of $95^{\text {th }}$ percentile temperatures at rates of around $0.2^{\circ} \mathrm{C}$ per decade is found in most of the region (Figure 4), with the exception of an arc of near zero warming extending north to south across Northeast China exhibiting strong trends in SCI and area equipped for irrigation (Figure 11). The spatial patterns of the SCI trend and the irrigation trend are highly correlated, due to the heavy reliance upon irrigation to facilitate increases in crop productivity and paddy rice production. Areas of Northeast China, where intensification and irrigation trends are strong, exhibit both increasing and decreasing area devoted to cropland. If we consider intensification and irrigation the primary drivers of cooling, this spatial overlap explains the counter-intuitive finding that both increasing and decreasing cropland area trends are associated with cooler extreme temperature trends. Precipitation trends exhibit no consistent association with extreme temperature trends. 
Our results are consistent with several recent studies suggesting land use has cooled summer temperatures in Northeast China. Hu et al. (2010) compare surface temperature observations to reanalysis products that do not include land use forcing - the "observation minus reanalysis" methodology - in order to estimate the influence of land use change. Similar to our results, they find cooling in maximum temperatures in Northeast China relative to reanalysis. Cao et al. (2015) force a regional climate model with remotely sensed changes in biophysical land surface parameters, including increases in leaf area index and vegetated fraction, and find cooling in cropped areas between 2001-2010. Zhao et al. (2016) find cooling and wetting trends from 1960-2014 associated with cultivated land fraction, with May-September daily maximum temperature trends in heavily cultivated areas $0.10^{\circ} \mathrm{C}$ per decade cooler than areas with minimal cropland.

A major uncertainty is the climatic influence of aerosol emissions and tropospheric ozone across Asia (Liao et al. 2015). While black carbon emissions and tropospheric ozone lead to warming, other pollutants are expected to have a cooling effect on surface temperatures. One set of model simulations (Chang et al. 2009) indicates that, on net, these forcings have minimal influence on summer temperatures but cause cooling during the winter months. However, Du et al. (2017) use an observationally-based attribution methodology to suggest suppression of average warm season air temperature trends in Northeast China due to declines in surface solar radiation. Detailed modeling studies are needed to understand the relative contributions of land use change, air pollution, and greenhouse gases on temperature trends.

\section{e. Southern East Asia}

Cropland intensification is associated with cooling in the Southern East Asia region, which includes areas of China, the Korean peninsula, and Japan south of $40^{\circ} \mathrm{N}$ to the Tropic of Cancer. Warming in $95^{\text {th }}$ percentile temperatures of around $0.2^{\circ} \mathrm{C}$ is seen over most of the region, with 
the exception of cooling over the major cropping area of the North China Plain and an absence of major warming extending south from this region through central China (Figure 4). The pattern of changes in temperature reflects that of SCI (Figure 12). Areas of negative SCI trends in South Korea and Japan are associated with the greatest rates of warming, whereas intensified landscapes in the North China Plain exhibit the most cooling. Similar to Northern East Asia, cropland intensification across much of this region is accompanied and supported by increases in irrigation, such that trends in the area equipped for irrigation are also significantly associated with reductions in $95^{\text {th }}$ percentile temperatures. Area equipped for irrigation is higher in the North China Plain than any other major cropping area examined (Table 3 ).

Our results for Southern East Asia are consistent with the land use influence identified in the analysis of observations and reanalysis by $\mathrm{Hu}$ et al. (2010) and the regional modeling of Cao et al. (2015). Bonfils and Lobell (2007) has also identified cooling of irrigated areas relative to surrounding unirrigated land in this region. Given that much of the heavily cultivated areas have experienced declines in cropland area while increasing productivity, decreases in cropland area are associated with reductions in extreme temperature trends. Precipitation trends appear unrelated to temperature trends. Aerosol emissions and tropospheric ozone are likely also important in this region. Although one modeling study indicates minimal net influence of pollutants on summer temperatures (Chang et al. 2009), other research points to a suppression of warm season air temperature trends in the North China Plain of over $0.1^{\circ} \mathrm{C}$ due to changes in surface solar radiation (Du et al. 2017). Since changes in evapotranspiration from land can also influence cloudiness, modeling studies exploring the interactions between pollution and land use change are necessary.

The major cropping area in this region is the North China Plain, an area where much of the land is double-cropped with winter wheat (Figure 12e,f). The intercropping period is centered on June according to the SIF data, and a large peak in photosynthetic activity occurs during July and 
August corresponding to growth of the second crop. These findings suggest that elevated evapotranspiration rates associated with intensification of the second crop are sufficient to contribute to a cooling of $95^{\text {th }}$ percentile temperatures over the three-month summer season. Jeong et al. (2014) note that temperatures during the intercropping period in double-cropped areas are higher than in areas planted with a single crop due to lower rates of evapotranspiration.

\section{f. Southern Australia}

In extratropical Australia, no substantial correlation exists between any of our explanatory variables and patterns of warming (Figure 13). The null result for intensification is to be expected given that winter wheat is dominant for the intensified production area in Western Australia. Winter seasonality is clearly demonstrated in the annual cycle of SIF and in the planting and harvest data. As a result, no significant variation exists in SCI. It is possible we would find associations between extreme temperatures and intensification if we extended our analysis to the winter growing season, as previous work focused on the wheat lands of Western Australia found elevated latent heat fluxes during the winter growing season over cropped areas relative to neighboring natural vegetation (Ray et al. 2003).

\section{g. Southern South America}

Data availability is limited in Southern South America (Figure 14), however several stations overlap with intensified cropland area in the Argentine Pampas west of Buenos Aires (Figure 3). Consistent with expectations, those stations that have positive SCI trends all exhibit $95^{\text {th }}$ percentile temperature trends that are negative or indistinguishable from zero, while the average $95^{\text {th }}$ percentile temperature trend across all other areas is towards warming. Strong relationships are not observed between $95^{\text {th }}$ percentile temperature trends and other predictors. Precipitation records 
in this region have a high number of missing observations, limiting our ability to analyze associations between temperature and precipitation trends. Our results are consistent with those of Nuñez et al. (2008), who find cooling of maximum temperatures and diurnal temperature range over the Pampas using an observation minus reanalysis approach. These authors also analyze precipitation trends using a more complete network of stations, finding elevated precipitation co-occurring with areas of cooling. Crop phenology in the Argentine Pampas is a mix of winter wheat and summer crops. Soybeans are the most dominant crop, and the area planted to soybeans has expanded substantially in recent years (Nuñez et al. 2008).

\section{h. Vegetation seasonality from NDVI data}

Global patterns of vegetation seasonality remain similar when calculating VEGsf using the GIMMS NDVI data instead of GOME-2 SIF data for the years 2007-2012; however, the magnitudes of NDVI-based VEGsf tend to be slightly lower (Figure 15a) than the SIF-based values since reflectance-based indices do not track the seasonality of vegetation growth as tightly as SIF (Guanter et al. 2014). Consistent associations are seen between SCI, calculated using NDVI-based VEGsf (SCI-NDVI), and summer temperature trends (Figure 16).

Trends in VEGsf using NDVI over 1982-2013 (Figure 15b) show weak, but positive, trends over the Western Corn Belt, the Canadian Prairies, and the Argentine Pampas. Positive trends presumably reflect cropland intensification, soybean expansion in Argentina, and declining summer fallow in Canada. Negative trends in the North China Plain could be the result of increased doublecropping (Ray and Foley 2013; Gray et al. 2014a; Jeong et al. 2014). If SCI could be calculated with yearly-varying VEGsf over the full record, the VEGsf trend analysis suggests that the magnitudes of SCI would be slightly higher in many cropped regions, with the exception of the North China Plain. However, the spatial patterns of intensified (high SCI trend) versus non-intensified 
(zero or low SCI trend) areas would likely be minimally affected, suggesting little bearing on our conclusions.

\section{Conclusions}

A significant relationship between intensification and cooler temperature extremes is found across all regions with substantial trends towards intensified summer cropping. Intensification is consistently the strongest land use predictor of extreme temperature trends, and is associated with cooling in both rainfed and irrigated cropping systems. In portions of Central North America and East Asia, growth in area equipped for irrigation is also closely related to cooling. Median $95^{\text {th }}$ percentile temperature trends in intensified areas are systematically $0.2-0.4^{\circ} \mathrm{C}$ per decade lower than in neighboring areas not experiencing intensification. Cooling associated with both intensification and increased irrigation can be understood as a consequence of increased latent cooling associated with elevated rates of evapotranspiration. Regional cooling can thus be added to the list of impacts associated with cropland intensification, alongside land demand (Matson and Vitousek 2006; Burney et al. 2010), nutrient application (Vitousek et al. 2009), the seasonality of atmospheric carbon dioxide (Gray et al. 2014b), water use (Siebert and Döll 2010), and water quality (Diaz and Rosenberg 2008).

Because extreme high temperatures are associated with crop damages, their amelioration by enhanced evapotranspiration raises the interesting question of how much of the agricultural intensification that we estimate, which is largely driven by improvement in yield, can be characterized as a positive feedback. There are, however, a number of extenuating circumstances regarding the operation of such a feedback. Cooling from evapotranspiration in rainfed areas is lost during drought conditions, leading to greater temperature shocks when soil moisture is depleted (Mueller et al. 2016). Increased soil water consumption could also increase crop exposure to dry spells, 
unless water is recycled through increased rainfall. Further, although extreme temperatures may be reduced over the summer months, temperature trends during key early-season reproductive periods are often towards warming (Gourdji et al. 2013). Higher atmospheric $\mathrm{CO}_{2}$ concentrations increase plant water use efficiency (Leakey et al. 2009), a change that may offset some of the otherwise expected increases in evapotranspiration. Also of note is that increased humidity levels may lead to little net change in heat index extremes for local human populations despite cooler air temperatures (Lobell et al. 2008).

Suppression of extreme temperatures by high-intensity croplands can be considered a climate regulation service (West et al. 2010), but the total climatic influence of any ecosystem is a function of both biophysical and biogeochemical climate forcings. On an annual basis, the modeling and accounting performed by Anderson-Teixeira et al. (2012) indicate US croplands and grasslands have similar climate regulation values, driven by high rates of evapotranspiration in cropland and high carbon storage in grasslands.

Further analyses are needed to understand the contribution of intensification-driven amelioration of temperature extremes on historical and future crop productivity. Crop yield models typically treat temperatures as an exogenous driver of productivity, although crop development and productivity play an important role in modifying surface energy fluxes (Williams and Torn 2015) and temperature extremes (Mueller et al. 2016). Moreover, the cooling effect of evapotranspiration on crop canopy temperature is much larger than the cooling effect on air temperature measured at standard weather stations (Siebert et al. 2014), and only recently has systematic modeling of canopy temperature been introduced into crop models to better reflect the impact of transpirationdriven cooling on crop heat stress (Webber et al. 2017). The degree to which management practices alter local weather and climate may have first-order implications for future yield trends. 
Acknowledgments. Funding provided by USDA AFRI fellowship 2016-67012-25208 to NDM and NSF Hydrological Sciences grant 1521210. We thank Alan Betts and two anonymous reviewers for helpful comments and feedback, and we thank Marena Lin, Karen McKinnon, and Martin Tingley for helpful conversations.

\section{References}

Adegoke, J. O., R. A. Pielke Sr., J. Eastman, R. Mahmood, and K. G. Hubbard, 2003: Impact of irrigation on midsummer surface fluxes and temperature under dry synoptic conditions: A regional atmospheric model study of the U.S. High Plains. Monthly Weather Review, 131, 556564.

Alter, R. E., Y. Fan, B. R. Lintner, and C. P. Weaver, 2015a: Observational evidence that Great Plains irrigation has enhanced summer precipitation intensity and totals in the Midwestern US. Journal of Hydrometeorology, 16, 1717-1735.

Alter, R. E., E.-S. Im, and E. A. B. Eltahir, 2015b: Rainfall consistently enhanced around the Gezira Scheme in East Africa due to irrigation. Nature Geoscience, 8 (10), 763-767.

Anderson-Teixeira, K. J., P. K. Snyder, T. E. Twine, S. V. Cuadra, M. H. Costa, and E. H. DeLucia, 2012: Climate-regulation services of natural and agricultural ecoregions of the Americas. Nature Climate Change, 2 (3), 177-181.

Barker, T., and Coauthors, 2005: Improving drought tolerance in maize. Plant Breeding Reviews, 25, 173-253.

Betts, A. K., 2004: Understanding hydrometeorology using global models. Bulletin of the American Meteorological Society, 85 (11), 1673-1688. 
Betts, A. K., R. Desjardins, D. Worth, and B. Beckage, 2014: Climate coupling between temperature, humidity, precipitation, and cloud cover over the Canadian Prairies. Journal of Geophysical Research-Atmospheres, 119 (23), 13 305-13 326.

Betts, A. K., R. Desjardins, D. Worth, and D. Cerkowniak, 2013: Impact of land use change on the diurnal cycle climate of the Canadian Prairies. Journal of Geophysical Research-Atmospheres, 118 (21), 11-996-12-011.

Betts, A. K., R. L. Desjardins, and D. E. Worth, 2016: The impact of clouds, land use and snow cover on climate in the Canadian Prairies. Advances in Science and Research, 13, 37-42.

Betts, A. K., A. B. Tawfik, and R. L. Desjardins, 2017: Revisiting Hydrometeorology Using Cloud and Climate Observations. Journal of Hydrometeorology, 18 (4), 939-955.

Bonan, G. B., 1999: Frost followed the plow: Impacts of deforestation on the climate of the United States. Ecological Applications, 9 (4), 1305-1315.

Bonan, G. B., 2001: Observational evidence for reduction of daily maximum temperature by croplands in the Midwest United States. Journal of Climate, 14 (11), 2430-2442.

Bonfils, C., and D. Lobell, 2007: Empirical evidence for a recent slowdown in irrigation-induced cooling. Proceedings of the National Academy of Sciences, 104 (34), 13 582-13 587.

Brovkin, V., S. Sitch, W. von Bloh, M. Claussen, E. Bauer, and W. Cramer, 2004: Role of land cover changes for atmospheric $\mathrm{CO}_{2}$ increase and climate change during the last 150 years. Global Change Biology, 10, 1-14.

Brown, P. J., and A. T. DeGaetano, 2013: Trends in US surface humidity, 1930-2010. Journal of Applied Meteorology and Climatology, 52 (1), 147-163. 
Burney, J., S. J. Davis, and D. B. Lobell, 2010: Greenhouse gas mitigation by agricultural intensification. Proceedings of the National Academy of Sciences, 107 (26), 12052.

Butler, E. E., and P. Huybers, 2015: Variations in the sensitivity of US maize yield to extreme temperatures by region and growth phase. Environmental Research Letters, 10, 1-8.

Cao, Q., D. Yu, M. Georgescu, Z. Han, and J. Wu, 2015: Impacts of land use and land cover change on regional climate: a case study in the agro- pastoral transitional zone of China. Environmental Research Letters, 10, 124025.

Chang, W., H. Liao, and H. Wang, 2009: Climate responses to direct radiative forcing of anthropogenic aerosols, tropospheric ozone, and long-lived greenhouse gases in eastern China over 1951-2000. Advances in Atmospheric Sciences, 26 (4), 748-762.

Chapin III, F. S., C. H. Walter, and D. T. Clarkson, 1988: Growth response of barley and tomato to nitrogen stress and its control by abscisic acid, water relations and photosynthesis. Planta, $173(3), 352-366$.

Davin, E. L., S. I. Seneviratne, P. Ciais, A. Olioso, and T. Want, 2014: Preferential cooling of hot extremes from cropland albedo management. Proceedings of the National Academy of Sciences, 111 (27), 9757-9761.

DeAngelis, A., F. Dominguez, Y. Fan, A. Robock, M. D. Kustu, and D. Robinson, 2010: Evidence of enhanced precipitation due to irrigation over the Great Plains of the United States. Journal of Geophysical Research, 115 (D15), 1-14.

Diaz, R. J., and R. Rosenberg, 2008: Spreading dead zones and consequences for marine ecosystems. Science, 321 (5891), 926-929. 
Diffenbaugh, N. S., 2009: Influence of modern land cover on the climate of the United States. Climate Dynamics, 33 (7-8), 945-958.

Du, J., K. Wang, J. Wang, and Q. Ma, 2017: Contributions of surface solar radiation and precipitation to the spatiotemporal patterns of surface and air warming in China from 1960 to 2003. Atmospheric Chemistry and Physics, 17 (8), 4931-4944.

Duvick, D. N., 2005: Genetic progress in yield of United States maize (Zea mays L.). Maydica, $50(3 / 4), 193$.

FAO, 2016: FAOSTAT database. United Nations Food and Agriculture Organization.

Feddema, J. J., K. W. Oleson, G. B. Bonan, L. O. Mearns, L. E. Buja, G. A. Meehl, and W. M. Washington, 2005: The importance of land-cover change in simulating future climates. Science, 310 (5754), 1674-1678.

Fischer, R. A., D. Rees, K. D. Sayre, Z.-M. Lu, A. G. Condon, and A. L. Saavedra, 1998: Wheat yield progress associated with higher stomatal conductance and photosynthetic rate, and cooler canopies. Crop Science, 38 (6), 1467-1475.

Foley, J. A., M. Costa, C. Delire, N. Ramankutty, and P. K. Snyder, 2003: Green surprise? How terrestrial ecosystems could affect earth's climate. Frontiers in Ecology and the Environment, $1(\mathbf{1}), 38-44$.

Gallaher, R. N., 1977: Soil moisture conservation and yield of crops no-till planted in rye. Soil Science Society Of America Journal, 41 (1), 145-147.

Gameda, S., B. Qian, C. A. Campbell, and R. L. Desjardins, 2007: Climatic trends associated with summerfallow in the Canadian Prairies. Agricultural and Forest Meteorology, 142 (2), 170-185. 
Gourdji, S. M., A. M. Sibley, and D. B. Lobell, 2013: Global crop exposure to critical high temperatures in the reproductive period: historical trends and future projections. Environmental Research Letters, 8 (2), 024041.

Gray, J., M. Friedl, S. Frolking, N. Ramankutty, A. Nelson, and M. K. Gumma, 2014a: Mapping Asian Cropping Intensity with MODIS. IEEE Journal of Selected Topics in Applied Earth Observations and Remote Sensing, 7 (8), 3373-3379.

Gray, J. M., S. Frolking, E. A. Kort, D. K. Ray, C. J. Kucharik, N. Ramankutty, and M. A. Friedl, 2014b: Direct human influence on atmospheric $\mathrm{CO}_{2}$ seasonality from increased cropland productivity. Nature, 515 (7527), 398-401.

Guanter, L., and Coauthors, 2014: Global and time-resolved monitoring of crop photosynthesis with chlorophyll fluorescence. Proceedings of the National Academy of Sciences, 111 (14), E1327-E1333.

Harding, K. J., and P. K. Snyder, 2012: Modeling the atmospheric response to irrigation in the Great Plains. Part I: General impacts on precipitation and the energy budget. Journal of Hydrometeorology, $13(6), 1667-1686$.

Hay, R., 1995: Harvest index: a review of its use in plant breeding and crop physiology. Annals of Applied Biology, 126 (1), 197-216.

Horowitz, J., R. Ebel, and K. Ueda, 2010: "No-till” farming is a growing practice. Tech. rep., Washington, DC.

Hu, Y., W. Dong, and Y. He, 2010: Impact of land surface forcings on mean and extreme temperature in eastern China. Journal of Geophysical Research, 115, D19 117. 
Huybers, P., K. A. McKinnon, A. Rhines, and M. Tingley, 2014: US daily temperatures: the meaning of extremes in the context of non-normality. Journal of Climate, 27, 7368-7384.

Jeong, S.-J., C.-H. Ho, S. Piao, J. Kim, P. Ciais, Y.-B. Lee, J.-G. Jhun, and S. K. Park, 2014: Effects of double cropping on summer climate of the North China Plain and neighbouring regions. Nature Climate Change, 4, 615-619.

Jiang, X., S. Kang, L. Tong, F. Li, D. Li, R. Ding, and R. Qiu, 2014: Crop coefficient and evapotranspiration of grain maize modified by planting density in an arid region of northwest China. Agricultural Water Management, 142, 135-143.

Joiner, J., and Coauthors, 2013: Global monitoring of terrestrial chlorophyll fluorescence from moderate spectral resolution near-infrared satellite measurements: methodology, simulations, and application to GOME-2. Atmospheric Measurement Techniques, 6, 2803-2823.

Jones, J. W., B. Zur, and J. M. Bennett, 1986: Interactive effects of water and nitrogen stresses on carbon and water vapor exchange of corn canopies. Agricultural and Forest Meteorology, 38 (1), 113-126.

Koenker, R., and G. Bassett, Jr, 1978: Regression quantiles. Econometrica, 46 (1), 33-50.

Kucharik, C. J., 2006: A Multidecadal Trend of Earlier Corn Planting in the Central USA. Agronomy Journal, 98 (6), 1544-7.

Kumar, S., J. Kinter III, P. A. Dirmeyer, Z. Pan, and J. Adams, 2013: Multidecadal climate variability and the "warming hole" in North America: Results from CMIP5 twentieth-and twentyfirst-century climate simulations. Journal of Climate, 26, 3511-3527.

Lark, T. J., J. M. Salmon, and H. K. Gibbs, 2015: Cropland expansion outpaces agricultural and biofuel policies in the United States. Environmental Research Letters, 10, 1-11. 
Leakey, A. D. B., E. A. Ainsworth, C. J. Bernacchi, A. Rogers, S. P. Long, and D. R. Ort, 2009: Elevated $\mathrm{CO} 2$ effects on plant carbon, nitrogen, and water relations: six important lessons from FACE. Journal Of Experimental Botany, 60 (10), 2859-2876.

Leibensperger, E. M., and Coauthors, 2012a: Climatic effects of 1950-2050 changes in US anthropogenic aerosols-Part 1: Aerosol trends and radiative forcing. Atmospheric Chemistry and Physics, 12 (7), 3333-3348.

Leibensperger, E. M., and Coauthors, 2012b: Climatic effects of 1950-2050 changes in US anthropogenic aerosols-Part 2: Climate response. Atmospheric Chemistry and Physics, 12 (7), $3349-3362$.

Liao, H., W. Chang, and Y. Yang, 2015: Climatic effects of air pollutants over China: A review. Advances in Atmospheric Sciences, 32, 115-139.

Lobell, D. B., C. J. Bonfils, L. M. Kueppers, and M. A. Snyder, 2008: Irrigation cooling effect on temperature and heat index extremes. Geophysical Research Letters, 35 (9), L09 705.

Lu, Y., J. Jin, and L. M. Kueppers, 2015: Crop growth and irrigation interact to influence surface fluxes in a regional climate-cropland model. Climate Dynamics, 117 (D06111), 1-17.

Mahmood, R., S. A. Foster, T. Keeling, K. G. Hubbard, C. Carlson, and R. Leeper, 2006: Impacts of irrigation on 20th century temperature in the northern Great Plains. Global And Planetary Change, 54 (1), 1-18.

Matson, P. A., and P. M. Vitousek, 2006: Agricultural intensification: Will land spared from farming be land spared for nature? Conservation Biology, 20 (3), 709-710. 
McKinnon, K. A., A. Rhines, M. P. Tingley, and P. Huybers, 2016: The changing shape of Northern Hemisphere summer temperature distributions. J Geophys Research - Atmospheres, 121, $1-20$

Menne, M. J., I. Durre, R. S. Vose, B. E. Gleason, and T. G. Houston, 2012: An overview of the global historical climatology network-daily database. Journal of Atmospheric and Oceanic Technology, 29 (7), 897-910.

Menne, M. J., and C. N. Williams, 2010: On the reliability of the US surface temperature record. Journal of Geophysical Research, 115, D11 108.

Milly, P., and K. A. Dunne, 2001: Trends in evaporation and surface cooling in the Mississippi River basin. Geophysical Research Letters, 28 (7), 1219-1222.

Monfreda, C., N. Ramankutty, and J. A. Foley, 2008: Farming the planet: 2. Geographic distribution of crop areas, yields, physiological types, and net primary production in the year 2000 . Global Biogeochemical Cycles, 22, GB1022.

Mueller, B., and S. I. Seneviratne, 2012: Hot days induced by precipitation deficits at the global scale. Proceedings of the National Academy of Sciences, 109 (31), 12 398-12 403.

Mueller, N. D., and S. Binder, 2015: Closing yield gaps: Consequences for the global food supply, environmental quality \& food security. Daedalus, 144 (4), 45-56.

Mueller, N. D., E. E. Butler, K. A. McKinnon, A. Rhines, M. P. Tingley, N. M. Holbrook, and P. Huybers, 2016: Cooling of US Midwest summer temperature extremes from cropland intensification. Nature Climate Change, 6, 317-322.

Mueller, N. D., J. S. Gerber, M. Johnston, D. K. Ray, N. Ramankutty, and J. A. Foley, 2012: Closing yield gaps through nutrient and water management. Nature, 490 (7419), 254-257. 
Nuñez, M. N., H. H. Ciapessoni, A. Rolla, E. Kalnay, and M. Cai, 2008: Impact of land use and precipitation changes on surface temperature trends in Argentina. Journal of Geophysical Research, 113, D06 111.

Oleson, K. W., G. B. Bonan, S. Levis, and M. Vertenstein, 2004: Effects of land use change on North American climate: impact of surface datasets and model biogeophysics. Climate Dynamics, 23, 117-132.

Pielke Sr., R. A., J. Adegoke, A. Beltrán-Przekurat, J. Lin, U. S. Nair, D. Niyogi, and T. E. Nobis, 2007: An overview of regional land-use and land-cover impacts on rainfall. Tellus Series BChemical And Physical Meteorology, 59B, 587-601.

Pielke Sr, R. A., and Coauthors, 2007: Unresolved issues with the assessment of multidecadal global land surface temperature trends. Journal of Geophysical Research, 112, D24S08.

Pielke Sr., R. A., and Coauthors, 2011: Land use/land cover changes and climate: modeling analysis and observational evidence. WIREs Climate Change, 2, 828-850.

Quayle, R. G., D. R. Easterling, and T. R. Karl, 1991: Effects of recent thermometer changes in the cooperative station network. Bulletin of the American Meteorological Society, 72 (11), $1718-1723$.

Raddatz, R. L., 1998: Anthropogenic vegetation transformation and the potential for deep convection on the Canadian prairies. Canadian Journal of Soil Science, 78 (4), 657-666.

Ramankutty, N., A. T. Evan, C. Monfreda, and J. A. Foley, 2008: Farming the planet: 1. Geographic distribution of global agricultural lands in the year 2000. Global Biogeochemical Cycles, 22, GB1003. 
Ramankutty, N., and J. A. Foley, 1999: Estimating historical changes in global land cover: Croplands from 1700 to 1992. Global Biogeochemical Cycles, 13 (4), 997-1027.

Ray, D. K., and J. A. Foley, 2013: Increasing global crop harvest frequency: recent trends and future directions. Environmental Research Letters, 8 (044041), 1-10.

Ray, D. K., N. D. Mueller, P. C. West, and J. A. Foley, 2013: Yield trends are insufficient to double global crop production by 2050. PLoS ONE, 8 (6), 1-8.

Ray, D. K., U. S. Nair, R. M. Welch, Q. Han, J. Zeng, W. Su, T. Kikuchi, and T. J. Lyons, 2003: Effects of land use in Southwest Australia: 1. Observations of cumulus cloudiness and energy fluxes. Journal of Geophysical Research, 104 (D14), 4414.

Ray, D. K., N. Ramankutty, N. D. Mueller, P. C. West, and J. A. Foley, 2012: Recent patterns of crop yield growth and stagnation. Nature Communications, 3, 1293.

Renka, R. J., 1997: Algorithm 772: STRIPACK: Delaunay triangulation and Voronoi diagram on the surface of a sphere. ACM Transactions on Mathematical Software, 23 (3), 416-434.

Rhines, A., M. P. Tingley, K. A. McKinnon, and P. Huybers, 2015: Decoding the precision of historical temperature observations. Quarterly Journal of the Royal Meteorological Society, 111.

Rhines, A., M. P. Tingley, K. A. McKinnon, and P. Huybers, 2016: Seasonally Resolved Distributional Trends of North American Temperatures. submitted.

Riggs, T. J., P. R. Hanson, N. D. Start, D. M. Miles, C. L. Morgan, and M. A. Ford, 1981: Comparison of Spring Barley Varieties Grown in England and Wales Between 1880 and 1980. Journal of Agricultural and Applied Economics, 97, 599-610. 
Roche, D., 2015: Stomatal conductance is essential for higher yield potential of C3 crops. Critical Reviews in Plant Sciences, 34 (4), 429-453.

Rudnick, D. R., and S. Irmak, 2014: Impact of nitrogen fertilizer on maize evapotranspiration crop coefficients under fully irrigated, limited irrigation, and rainfed settings. Journal of Irrigation and Drainage Engineering, 140 (12), 1-15.

Sacks, W. J., D. Deryng, J. A. Foley, and N. Ramankutty, 2010: Crop planting dates: an analysis of global patterns. Global Ecology and Biogeography, 19 (5), 607-620.

Sandstrom, M. A., R. G. Lauritsen, and D. Changnon, 2004: A central-US summer extreme dewpoint climatology (1949-2000). Physical Geography, 25 (3), 191-207.

Seneviratne, S. I., T. Corti, E. L. Davin, M. Hirschi, E. B. Jaeger, I. Lehner, B. Orlowsky, and A. J. Teuling, 2010: Investigating soil moisture-climate interactions in a changing climate: A review. Earth-Science Reviews, 99 (3-4), 125-161.

Siebert, S., and P. Döll, 2010: Quantifying blue and green virtual water contents in global crop production as well as potential production losses without irrigation. Journal of Hydrology, 384 (34), 198-217.

Siebert, S., F. Ewert, E. E. Rezaei, H. Kage, and R. Graß, 2014: Impact of heat stress on crop yield — on the importance of considering canopy temperature. Environmental Research Letters, 9 (4), 044012.

Siebert, S., M. Kummu, M. Porkka, P. Döll, N. Ramankutty, and B. R. Scanlon, 2015: A global data set of the extent of irrigated land from 1900 to 2005. Hydrology and Earth System Sciences, 19, $1521-1545$. 
Spera, S. A., G. L. Galford, M. T. Coe, M. N. Macedo, and J. F. Mustard, 2016: Land-use change affects water recycling in Brazil's last agricultural frontier. Global Change Biology.

Tilman, G. D., K. G. Cassman, P. A. Matson, R. L. Naylor, and S. Polasky, 2002: Agricultural sustainability and intensive production practices. Nature, 418 (6898), 671-677.

Tucker, C. J., 2014: AVHRR NDVI3g. NASA.

Twine, T. E., C. J. Kucharik, and J. A. Foley, 2004: Effects of land cover change on the energy and water balance of the Mississippi River basin. Journal of Hydrometeorology, 5 (4), 640-655.

USDA, 1994: Major world crop areas and climatic profiles. Agricultural Handbook No. 664, United States Department of Agriculture, Washington, DC.

Vitousek, P. M., and Coauthors, 2009: Agriculture. Nutrient imbalances in agricultural development. Science, 324 (5934), 1519-1520.

Webber, H., and Coauthors, 2017: Canopy temperature for simulation of heat stress in irrigated wheat in a semi-arid environment: A multi-model comparison. Field Crops Research, 202, 2135.

West, P. C., G. T. Narisma, C. C. Barford, C. J. Kucharik, and J. A. Foley, 2010: An alternative approach for quantifying climate regulation by ecosystems. Frontiers in Ecology and the Environment, 9 (2), 126-133.

Williams, I. N., and M. S. Torn, 2015: Vegetation controls on surface heat flux partitioning, and land - atmosphere coupling. Geophysical Research Letters, 42, 1-9.

Zhao, N., S. Han, D. Xu, J. Wang, and H. Yu, 2016: Cooling and wetting effects of agricultural development on near-surface atmosphere over northeast China. Advances in Meteorology, 2016 (7), 1-12. 


\section{LIST OF TABLES}

Table 1. Historical and modern harvest index (HI) values by crop. All modern HI values are drawn from the compilation by Monfreda et al. (2008), and references for the historical values are listed in the table.

Table 2. The percent of summer station-days reporting maximum temperature observations across all weather stations, listed by region and time period. Summer is defined as June-August in the Northern Hemisphere and December-February in the Southern Hemisphere.

Table 3. Average cropland area, area equipped for irrigation (AEI), vegetation summer fraction (VEGsf) calculated from chlorophyll fluorescence data, summer cropping intensity index (SCI), and summer precipitation for major cropping areas. The major cropping areas are defined by the green grid cells in Figure 1. Each average is calculated over the full temporal range of the data, from 19612007 for cropland area, 1961-2005 for AEI, 1961-2008 for SCI, 1961-2014 for precipitation. VEGsf is calculated over the recent years of 2007-2012. No precipitation data is shown for the Argentine Pampas due to data limitations. 
TABLE 1. Historical and modern harvest index (HI) values by crop. All modern HI values are drawn from the compilation by Monfreda et al. (2008), and references for the historical values are listed in the table.

\begin{tabular}{llll}
\hline crop type & historical HI & reference & modern HI \\
\hline barley & 0.38 & Riggs et al. (1981) & 0.49 \\
maize & - & - & 0.45 \\
rapeseed & - & - & 0.30 \\
rice & 0.30 & Hay (1995) & 0.40 \\
soybean & - & - & 0.42 \\
wheat & 0.33 & Hay (1995) & 0.39 \\
\hline
\end{tabular}


TABLE 2. The percent of summer station-days reporting maximum temperature observations across all weather stations, listed by region and time period. Summer is defined as June-August in the Northern Hemisphere and December-February in the Southern Hemisphere.

\begin{tabular}{ccccc}
\hline & \multicolumn{5}{c}{ time period } \\
region & $\mathbf{1 9 6 1 - 1 9 6 9}$ & $\mathbf{1 9 7 0 - 1 9 7 9}$ & $\mathbf{1 9 8 0 - 1 9 8 9}$ & $\mathbf{1 9 9 0 - 2 0 1 4}$ \\
\hline Central North America & 95.6 & 96.4 & 93.6 & 83.7 \\
Northern North America & 90.8 & 97.0 & 95.3 & 70.8 \\
Western Europe & 98.0 & 98.9 & 98.6 & 82.6 \\
Northern East Asia & 98.1 & 98.0 & 99.1 & 92.6 \\
Southern East Asia & 99.5 & 100.0 & 100.0 & 89.9 \\
Southern Australia & 95.3 & 95.8 & 95.8 & 76.3 \\
Southern South America & 95.8 & 98.8 & 95.4 & 66.0 \\
\hline
\end{tabular}


TABLE 3. Average cropland area, area equipped for irrigation (AEI), vegetation summer fraction (VEGsf) calculated from chlorophyll fluorescence data, summer cropping intensity index (SCI), and summer precipitation for major cropping areas. The major cropping areas are defined by the green grid cells in Figure 1. Each average is calculated over the full temporal range of the data, from 1961-2007 for cropland area, 1961-2005 for AEI, 1961-2008 for SCI, 1961-2014 for precipitation. VEGsf is calculated over the recent years of 2007-2012. No precipitation data is shown for the Argentine Pampas due to data limitations.

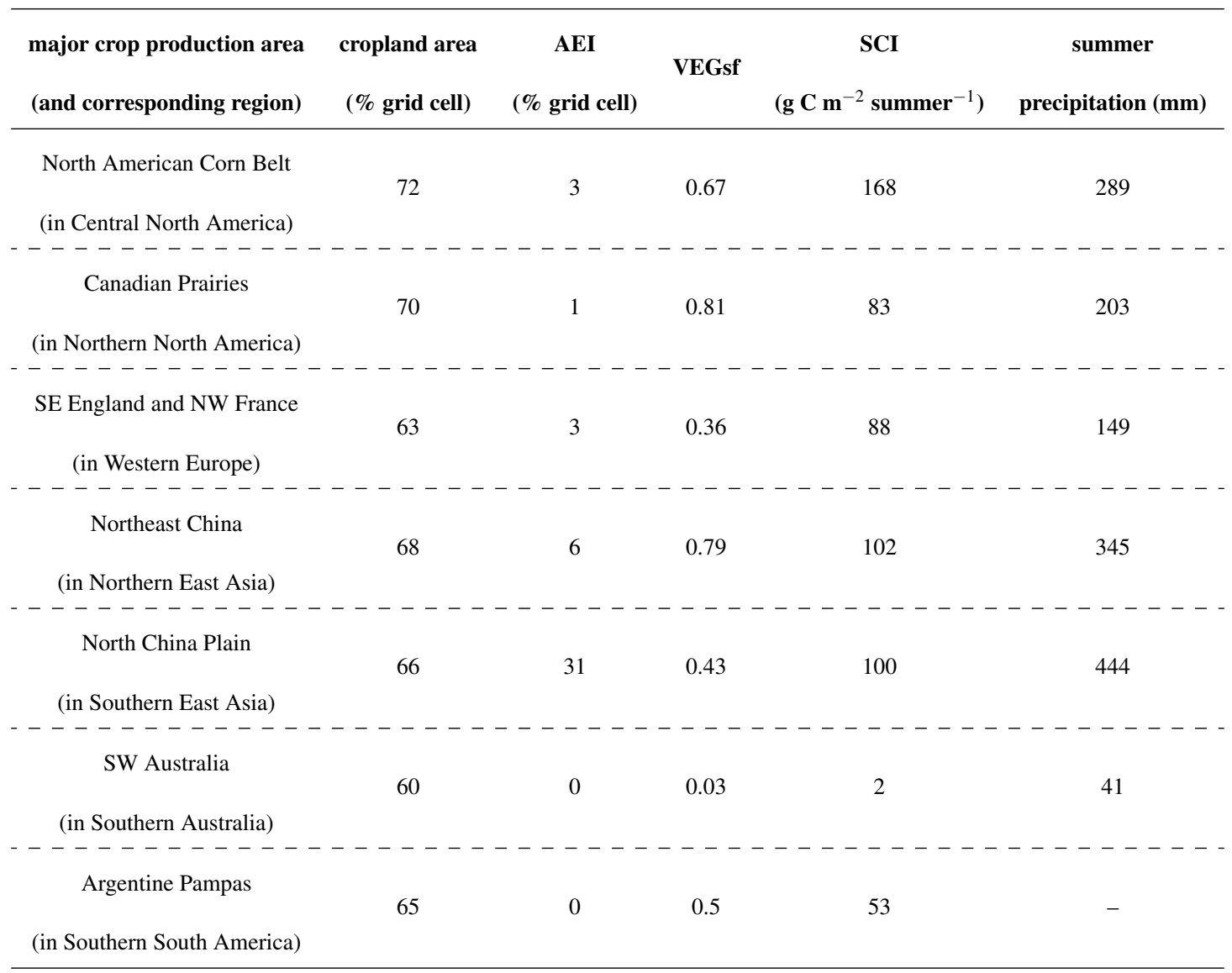




\section{LIST OF FIGURES}

Fig. 1. Regions examined for associations between agricultural land use, precipitation, and extreme temperatures are shown in orange boxes and include Central North America, Northern North America, Western Europe, Northern East Asia, Southern East Asia, Southern Australia, and Southern South America. Within each region, a major cropping area is identified (in green), and these areas are used to characterize patterns of crop phenology within each region. Major cropping areas are defined as areas where the trend in our Summer Cropping Intensity index, "SCI" (defined in the section Summer cropping intensity trends), is $>1 \mathrm{~g}$ $\mathrm{C} \mathrm{m}^{-2}$ summer ${ }^{-2}$, cropland area $>50 \%$ grid cell area, and grid cell centers are within the bounds identified by the dashed lines.

Fig. 2. (a) Trends in cropland area for 1961-2007, (b) trends in area equipped for irrigation for 1961-2005, and (c) trends in summer precipitation for 1961-2014. Cropland area is from a historical dataset based on satellite and agricultural census data (Ramankutty and Foley 1999). Area equipped for irrigation is determined from agricultural census and land use records as recorded by Siebert et al. (2015). Precipitation data is from the Global Historical Climatology Network - Daily weather station dataset, and dot sizes are scaled according to Voronoi polygons surrounding each station. Summer seasons are defined as June-August in the Northern Hemisphere and December-February in the Southern Hemisphere.

Fig. 3. (a) Trends in area-normalized net primary productivity (NPPan) over 1961-2014, calculated using harvested area and yield records for six major crops: maize, wheat, rice, soybean, barley, and rapeseed. (b) The fraction of vegetation growth occurring during the summer, the vegetation summer fraction (VEGsf), calculated using sun-induced chlorophyll fluorescence (SIF) from the GOME-2 satellite. (c) Trends in the Summer Cropping Intensity index (SCI), calculated by multiplying NPPan trends and VEGsf.

Fig. 4. Quantile regression trends in $95^{\text {th }}$ percentile summer daily maximum temperatures from 1961-2014. Temperature data is from the Global Historical Climatology Network - Daily weather station dataset, and dot sizes are scaled according to Voronoi polygons surrounding each station. Summer seasons are defined as June-August in the Northern Hemisphere and December-February in the Southern Hemisphere.

Fig. 5. An example showing local crop and land use characteristics, weather data, and $95^{\text {th }}$ percentile maximum temperature trends for a weather station in Redwood County, MN, USA. (a) Crop harvested areas and (b) crop yields for all crops (of the six considered) where the maximum harvested area was greater than $1 \%$ of grid cell area. (c) The fraction of vegetation growth occurring during the summer (VEGsf), as calculated using SIF and NDVI. (d) NPPan and SCI, calculated using crop harvested area, crop yield, and SIF-based VEGsf according to Equations 1-4. (e) Cropland area, area equipped for irrigation, and summer (June-August) precipitation are also considered as predictors of changing extreme temperatures. (f) Daily summer maximum temperature observations, with the $95^{\text {th }}$ percentile quantile regression trend overlaid in maroon. The quantile regression trend is calculated after adding jitter to the observations to account for rounding artifacts. (g) A histogram of $95^{\text {th }}$ percentile maximum temperature trends derived from a block-bootstrap resampling of yearly observations. The trend line fit using all the data is shown in the thick maroon line, and dashed lines indicate the $95 \%$ confidence interval on the trend. All land use data are extracted for the nearest grid cell to the weather station, and gridded data are used at the original resolution of each dataset ( 5 arc-minute for the crop harvested area and yield data, 5 arc-minute for the irrigation data, and half-degree for the cropland area data). 
Fig. 6. Trends in Central North American temperature extremes grouped according to candidate predictor variables: (a) cropland area, (b) area equipped for irrigation, (c) summer precipitation, and (d) SCI. Data points are from weather stations that have been associated with local (nearest half-degree grid box) trends in land use characteristics. Weather stations are evenly binned according to land use or precipitation trends. Boxplots display the full range of temperature trends across stations for each bin, with the boxes containing the interquartile range, whiskers extending up to $1.5 x$ the interquartile range, and crosses indicating outliers beyond this range. Asterisks indicate that $95^{\text {th }}$ percentile temperature trends for a given bin significantly differ from those in the control group (gray box, centered on zero trend) at the $\mathrm{p}<0.05$ level or $\mathrm{p}<0.01$ for double asterisks. $\mathrm{X}$-axis values are generally the mid-points of each bin, although edge bins include weather stations associated with outlier trends in each explanatory variable. Box widths are proportional to the area associated with the constituent weather stations, except for the control bins that are narrowed by a factor of five for legibility. Box colors are consistent with the maps in Figures 2 and 3.

Fig. 7. Seasonal patterns of vegetative development for the major crop production areas of the Central North American Corn Belt. (a) Median monthly SIF and the interquartile range of monthly values calculated across available years. (b) Average crop seasons - from planting to harvest - for major crops in the region from data compiled by Sacks et al. (2010). Ranges of typical planting and harvest dates are indicated with the dashed black lines. Harvested area of major crops (Monfreda et al. 2008) in each region are indicated next to crop names, and are used to scale the width of the boxes devoted to each crop. Given that two seasons of wheat are present, bar area is divided equally between the two categories since crop harvested area data are not separated by season. Both SIF and crop season data are weighted spatial averages across those grid cells indicated for the Central North America region in Figure 1, where weights are cropland area from Ramankutty et al. (2008) for the SIF plot and individual crop harvested areas from Monfreda et al. (2008) for the crop season plot.

Fig. 8. Same as in Figures 6 and 7, but for Northern North America. One outlier station where the $95^{\text {th }}$ percentile summer temperature trend was $>2^{\circ} \mathrm{C}$ per decade has been removed from the boxplots and statistical analysis. Phenology is shown in (e) and (f) for the major crop production areas of the Canadian Prairies.

Fig. 9. Disaggregating contributions to SCI trends in the Canadian Prairies. (a) Trends in SCI calculated using yearly varying harvested area and average crop yields over the years 19612008. (b) Trends in SCI calculated using yearly varying yields and average harvested area. Note that the scale is truncated relative to Figure 3 to better highlight differences between the calculations.

Fig. 10. Same as in Figures 6 and 7, but for Western Europe. Phenology is shown in (e) and (f) for the major crop production areas of Southern England and Northwest France.

Fig. 11. Same as in Figures 6 and 7, but for Northern East Asia. Phenology is shown in (e) and (f) for the major crop production areas of Northeast China.

Fig. 12. Same as in Figures 6 and 7, but for Southern East Asia. Phenology is shown in (e) and (f) for the major crop production areas of the North China Plain.

Fig. 13. Same as in Figures 6 and 7, but for Southern Australia. Phenology is shown in (e) and (f) for the major crop production areas of Western Australia. 
Fig. 14. Same as in Figures 6 and 7, but for Southern South America. Phenology is shown in (d) and (e) for the major crop production areas of the Argentine Pampas.

Fig. 15. (a) VEGsf calculated using the GIMMS NDVI data over the years 2007-2012, consistent with the calculation for SIF. (b) The decadal trend in VEGsf calculated using GIMMS NDVI data over the years 1982-2013. Areas where VEGsf was not calculated using the SIF data are masked.

Fig. 16. (a) The summer cropping intensity index calculated using GIMMS NDVI data instead of SIF to calculate the vegetation summer fraction (SCI-NDVI). Associations between SCINDVI and $95^{\text {th }}$ percentile summer temperature trends for (b) Central North America, (c) Northern North America, (d) Northern East Asia, (e) Southern East Asia, (f) and Southern South America. 


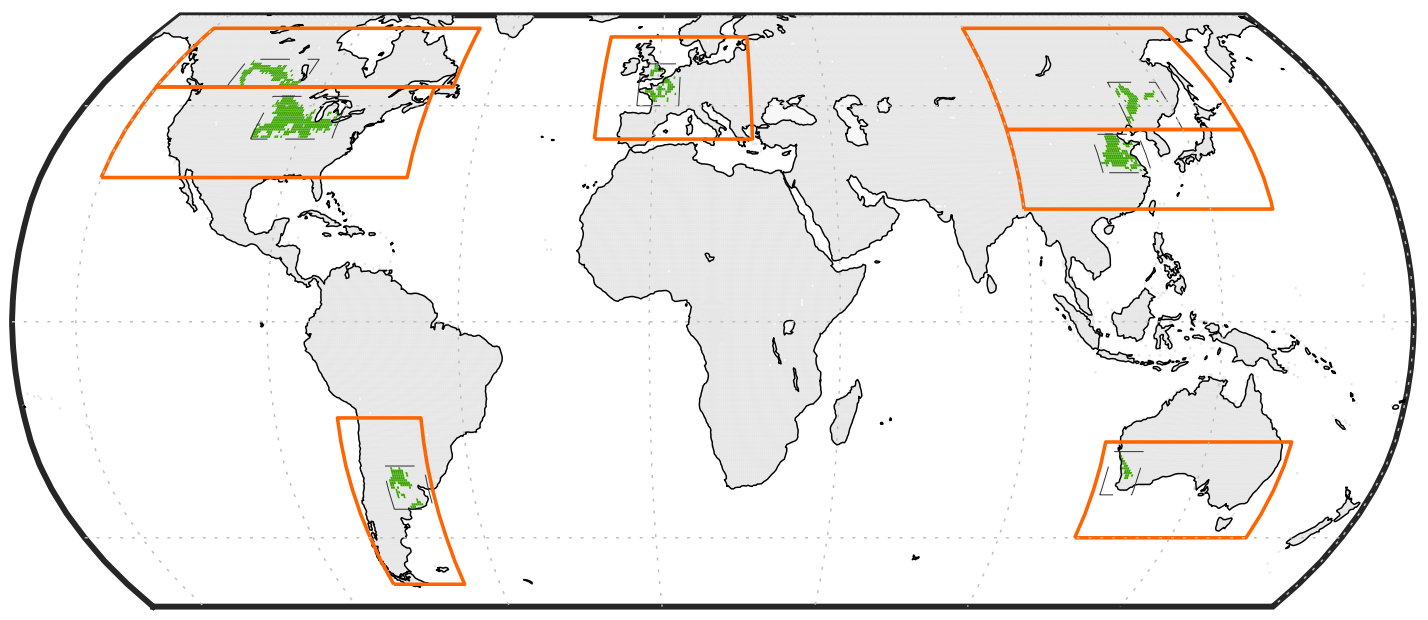

FIG. 1. Regions examined for associations between agricultural land use, precipitation, and extreme temperatures are shown in orange boxes and include Central North America, Northern North America, Western Europe, Northern East Asia, Southern East Asia, Southern Australia, and Southern South America. Within each region, a major cropping area is identified (in green), and these areas are used to characterize patterns of crop phenology within each region. Major cropping areas are defined as areas where the trend in our Summer Cropping Intensity index, "SCI" (defined in the section Summer cropping intensity trends), is $>1 \mathrm{~g} \mathrm{C} \mathrm{m}^{-2}$ summer $^{-2}$, cropland area $>50 \%$ grid cell area, and grid cell centers are within the bounds identified by the dashed lines. 

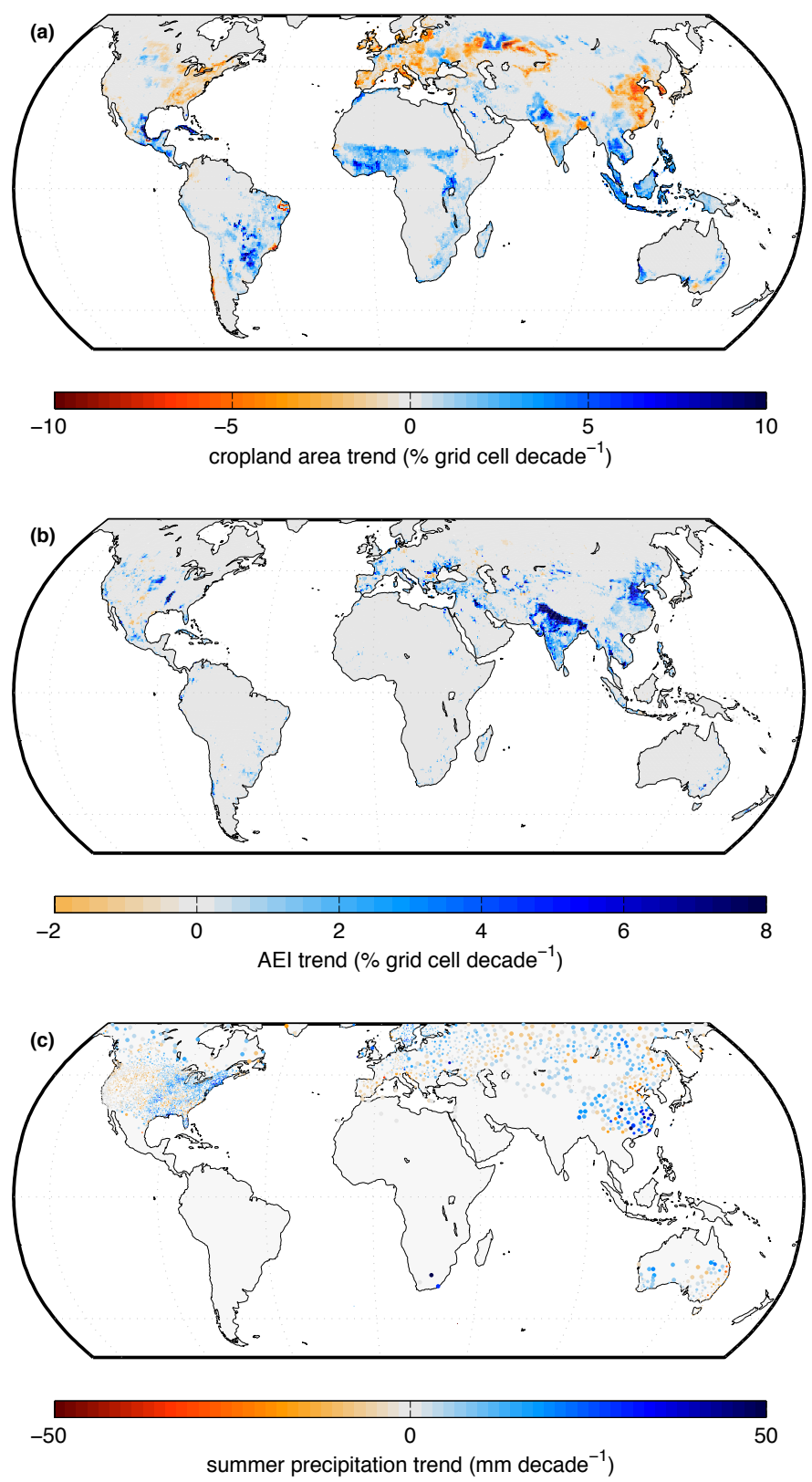

FIG. 2. (a) Trends in cropland area for 1961-2007, (b) trends in area equipped for irrigation for 1961-2005, and (c) trends in summer precipitation for 1961-2014. Cropland area is from a historical dataset based on satellite and agricultural census data (Ramankutty and Foley 1999). Area equipped for irrigation is determined from agricultural census and land use records as recorded by Siebert et al. (2015). Precipitation data is from the Global Historical Climatology Network - Daily weather station dataset, and dot sizes are scaled according to Voronoi polygons surrounding each station. Summer seasons are defined as June-August in the Northern Hemisphere and December-February in the Southern Hemisphere. 

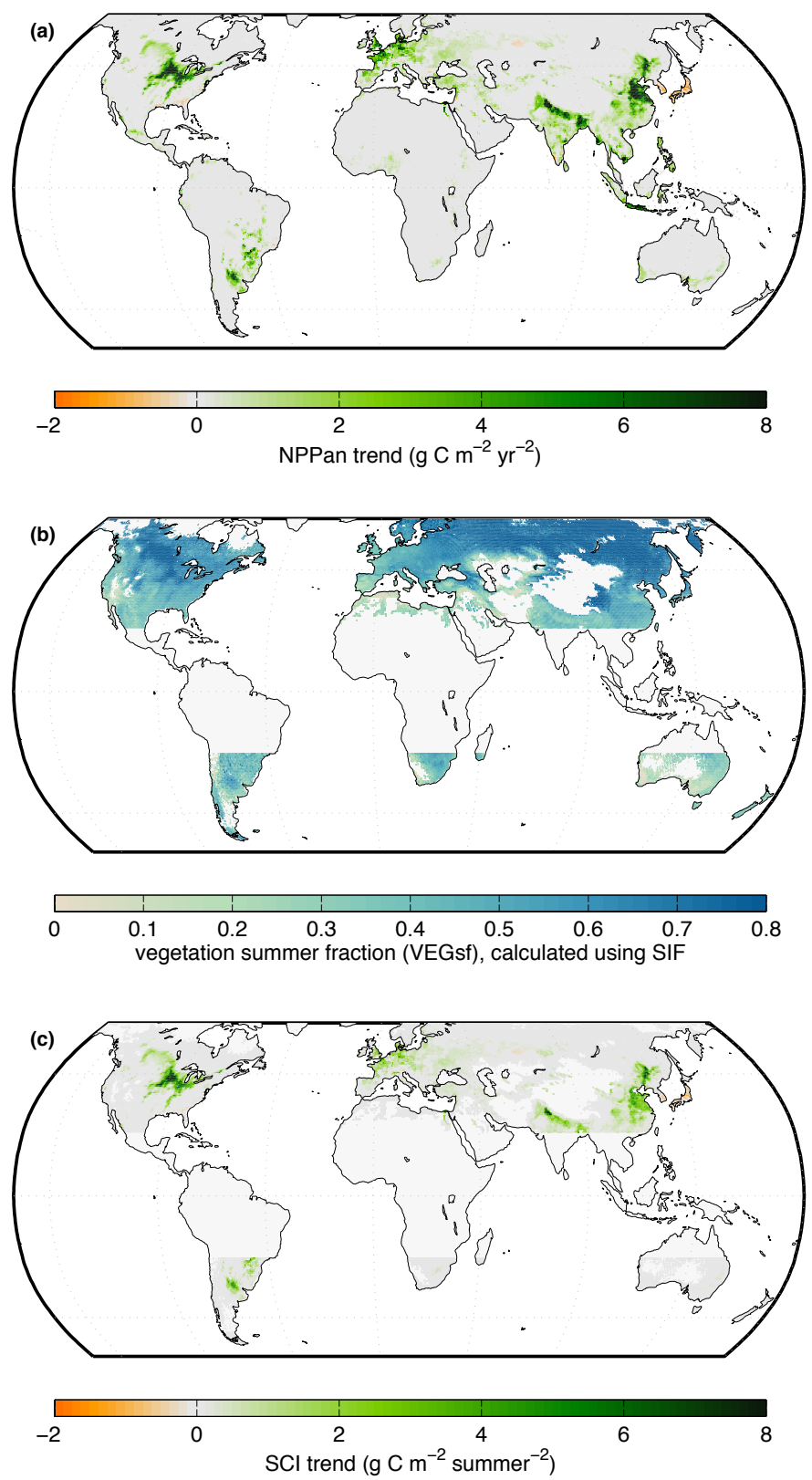

FIG. 3. (a) Trends in area-normalized net primary productivity (NPPan) over 1961-2014, calculated using harvested area and yield records for six major crops: maize, wheat, rice, soybean, barley, and rapeseed. (b) The fraction of vegetation growth occurring during the summer, the vegetation summer fraction (VEGsf), calculated using sun-induced chlorophyll fluorescence (SIF) from the GOME-2 satellite. (c) Trends in the Summer Cropping Intensity index (SCI), calculated by multiplying NPPan trends and VEGsf. 


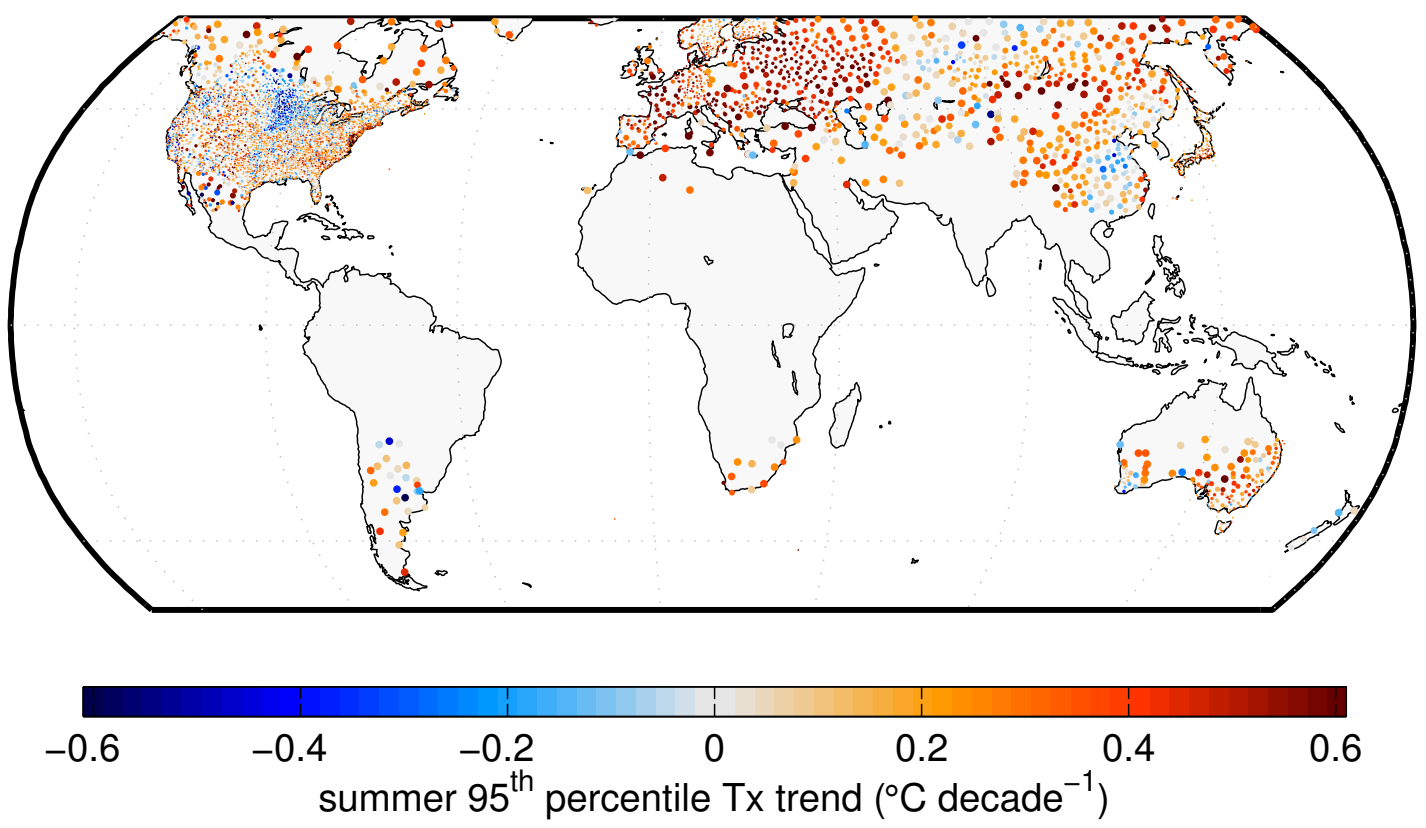

FIG. 4. Quantile regression trends in $95^{\text {th }}$ percentile summer daily maximum temperatures from 1961-2014.

Temperature data is from the Global Historical Climatology Network - Daily weather station dataset, and dot sizes are scaled according to Voronoi polygons surrounding each station. Summer seasons are defined as JuneAugust in the Northern Hemisphere and December-February in the Southern Hemisphere. 

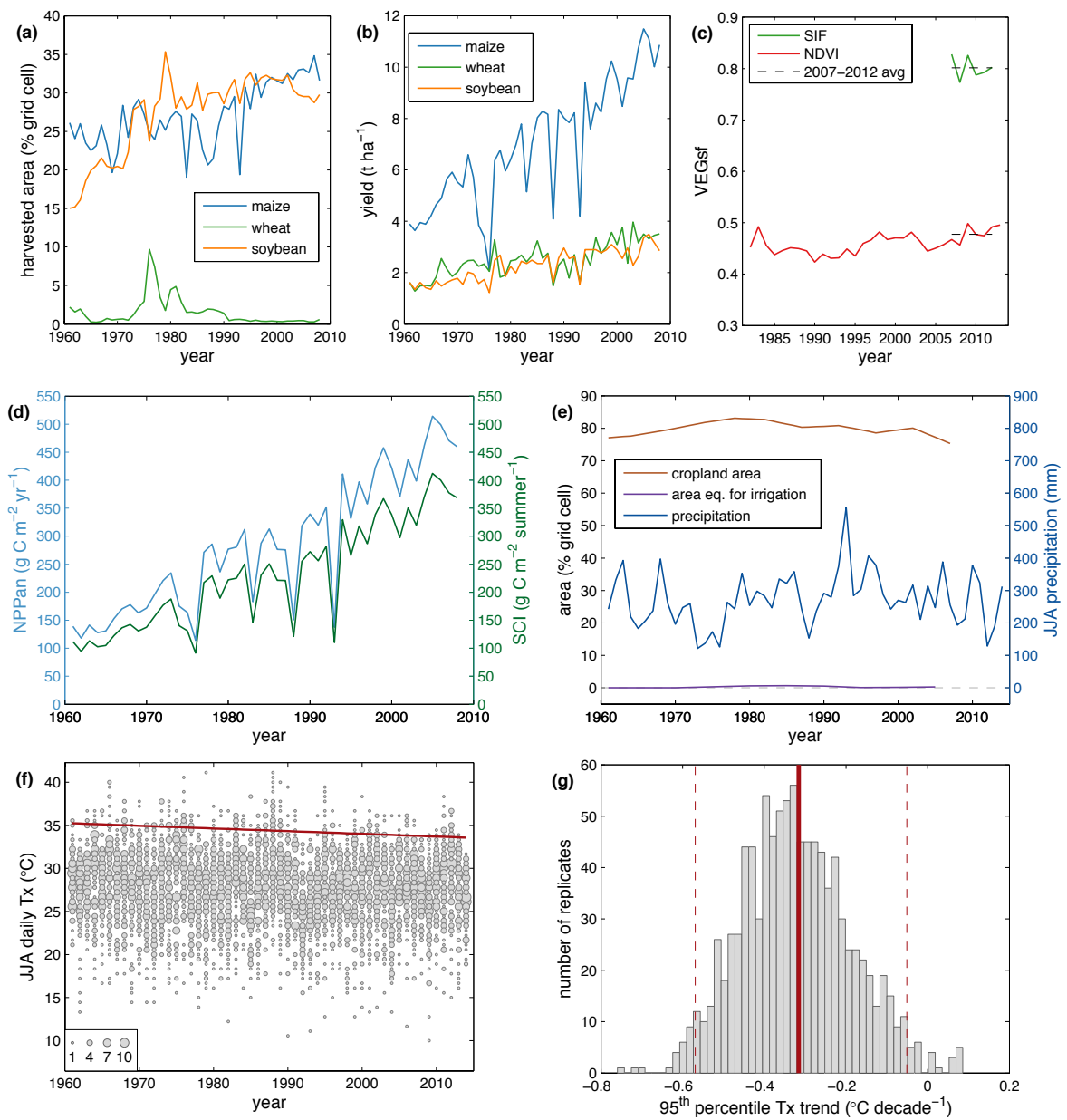

FIG. 5. An example showing local crop and land use characteristics, weather data, and $95^{\text {th }}$ percentile maximum temperature trends for a weather station in Redwood County, MN, USA. (a) Crop harvested areas and (b) crop yields for all crops (of the six considered) where the maximum harvested area was greater than $1 \%$ of grid cell area. (c) The fraction of vegetation growth occurring during the summer (VEGsf), as calculated using SIF and NDVI. (d) NPPan and SCI, calculated using crop harvested area, crop yield, and SIF-based VEGsf according to Equations 1-4. (e) Cropland area, area equipped for irrigation, and summer (June-August) precipitation are also considered as predictors of changing extreme temperatures. (f) Daily summer maximum temperature observations, with the $95^{\text {th }}$ percentile quantile regression trend overlaid in maroon. The quantile regression trend is calculated after adding jitter to the observations to account for rounding artifacts. (g) A histogram of $95^{\text {th }}$ percentile maximum temperature trends derived from a block-bootstrap resampling of yearly observations. The trend line fit using all the data is shown in the thick maroon line, and dashed lines indicate the $95 \%$ confidence interval on the trend. All land use data are extracted for the nearest grid cell to the weather station, and gridded data are used at the original resolution of each dataset ( 5 arc-minute for the crop harvested area and yield data, 5 arc-minute for the irrigation data, and half-degree for the cropland area data). 

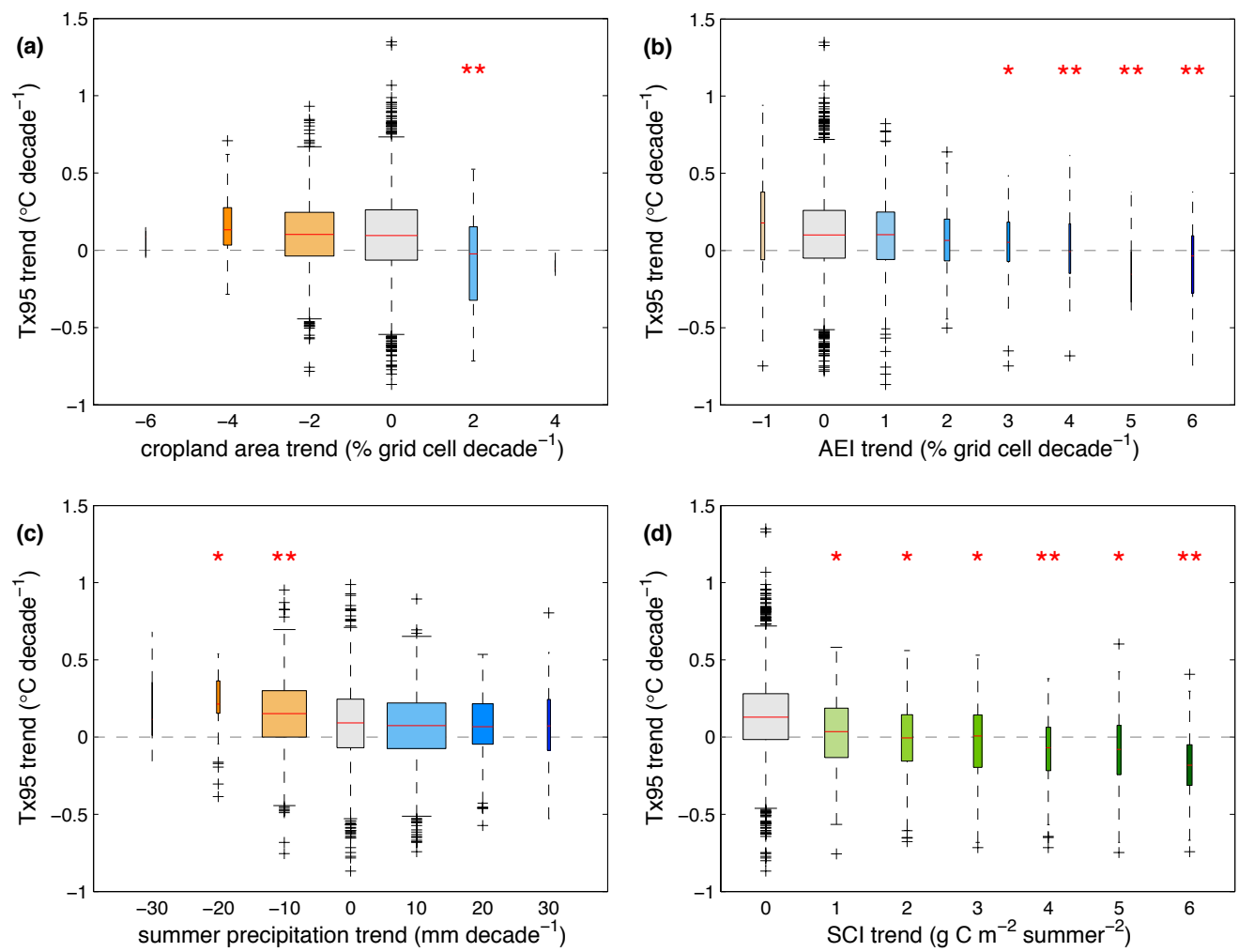

FIG. 6. Trends in Central North American temperature extremes grouped according to candidate predictor variables: (a) cropland area, (b) area equipped for irrigation, (c) summer precipitation, and (d) SCI. Data points are from weather stations that have been associated with local (nearest half-degree grid box) trends in land use characteristics. Weather stations are evenly binned according to land use or precipitation trends. Boxplots display the full range of temperature trends across stations for each bin, with the boxes containing the interquartile range, whiskers extending up to $1.5 \mathrm{x}$ the interquartile range, and crosses indicating outliers beyond this range. Asterisks indicate that $95^{\text {th }}$ percentile temperature trends for a given bin significantly differ from those in the control group (gray box, centered on zero trend) at the $\mathrm{p}<0.05$ level or $\mathrm{p}<0.01$ for double asterisks. $\mathrm{X}$-axis values are generally the mid-points of each bin, although edge bins include weather stations associated with outlier trends in each explanatory variable. Box widths are proportional to the area associated with the constituent weather stations, except for the control bins that are narrowed by a factor of five for legibility. Box colors are consistent with the maps in Figures 2 and 3. 

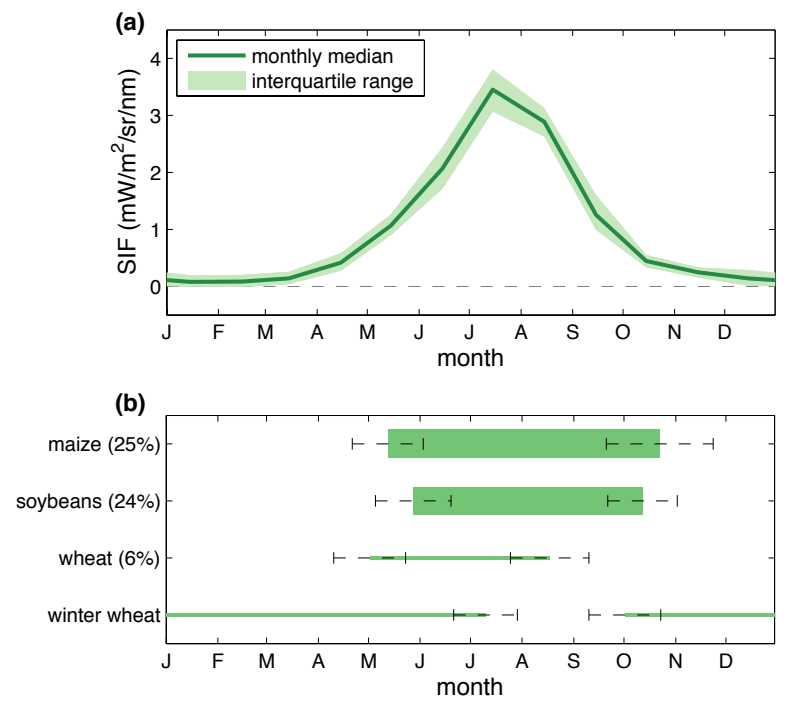

FIG. 7. Seasonal patterns of vegetative development for the major crop production areas of the Central North American Corn Belt. (a) Median monthly SIF and the interquartile range of monthly values calculated across available years. (b) Average crop seasons - from planting to harvest - for major crops in the region from data compiled by Sacks et al. (2010). Ranges of typical planting and harvest dates are indicated with the dashed black lines. Harvested area of major crops (Monfreda et al. 2008) in each region are indicated next to crop names, and are used to scale the width of the boxes devoted to each crop. Given that two seasons of wheat are present, bar area is divided equally between the two categories since crop harvested area data are not separated by season. Both SIF and crop season data are weighted spatial averages across those grid cells indicated for the Central North America region in Figure 1, where weights are cropland area from Ramankutty et al. (2008) for the SIF plot and individual crop harvested areas from Monfreda et al. (2008) for the crop season plot. 

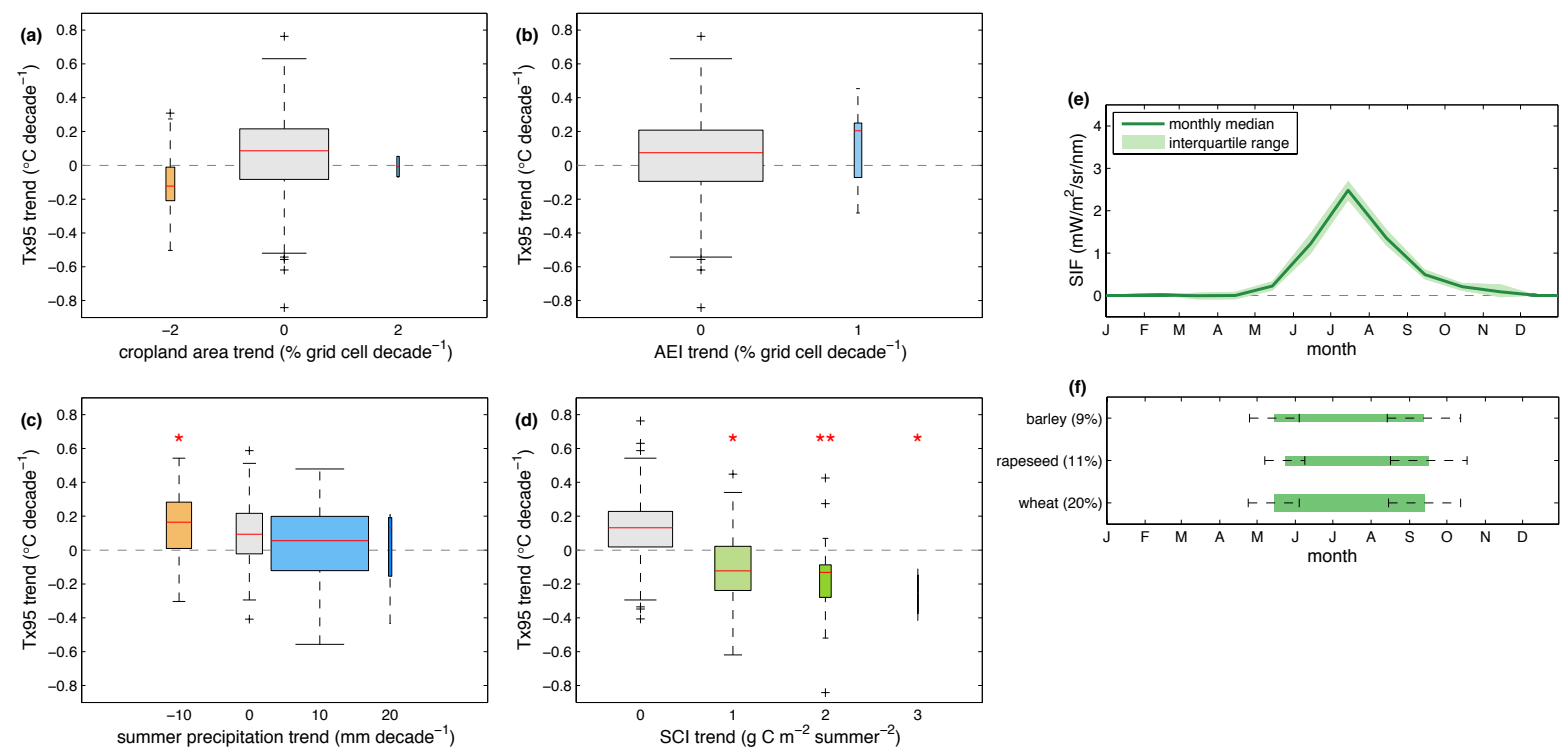

FIG. 8. Same as in Figures 6 and 7, but for Northern North America. One outlier station where the 95 percentile summer temperature trend was $>2{ }^{\circ} \mathrm{C}$ per decade has been removed from the boxplots and statistical analysis. Phenology is shown in (e) and (f) for the major crop production areas of the Canadian Prairies. 

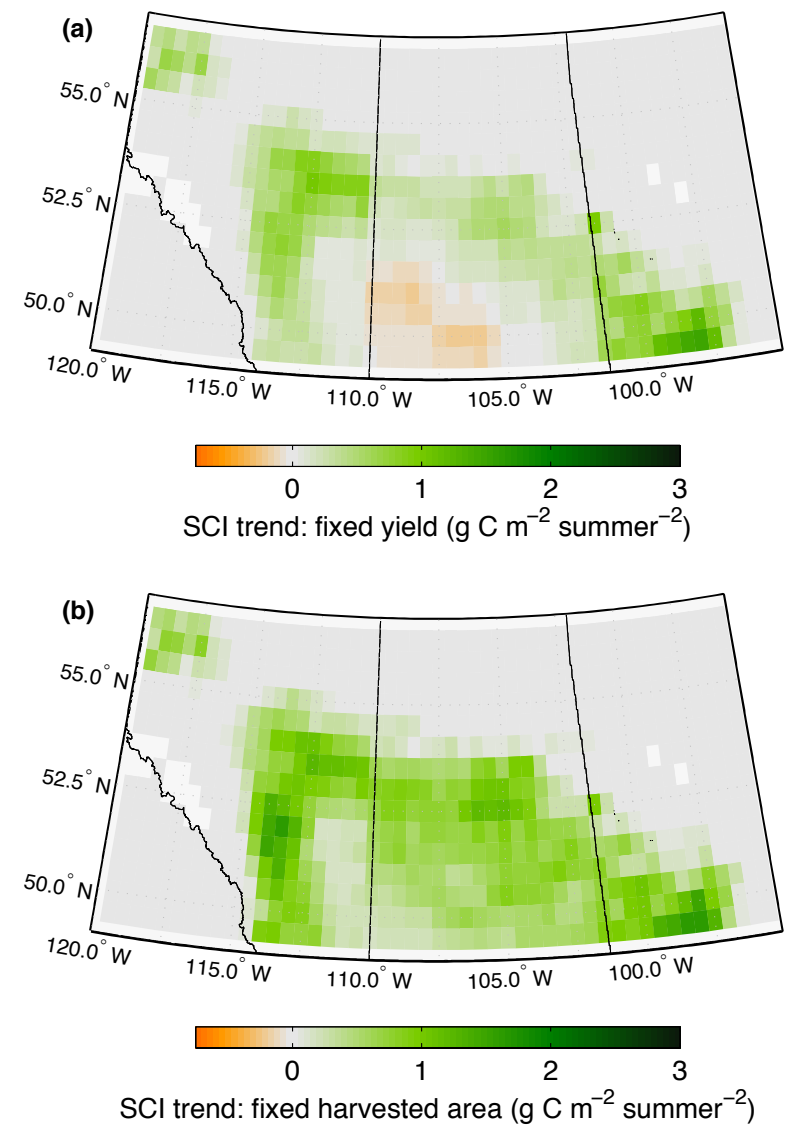

FIG. 9. Disaggregating contributions to SCI trends in the Canadian Prairies. (a) Trends in SCI calculated using yearly varying harvested area and average crop yields over the years 1961-2008. (b) Trends in SCI calculated using yearly varying yields and average harvested area. Note that the scale is truncated relative to Figure 3 to better highlight differences between the calculations. 

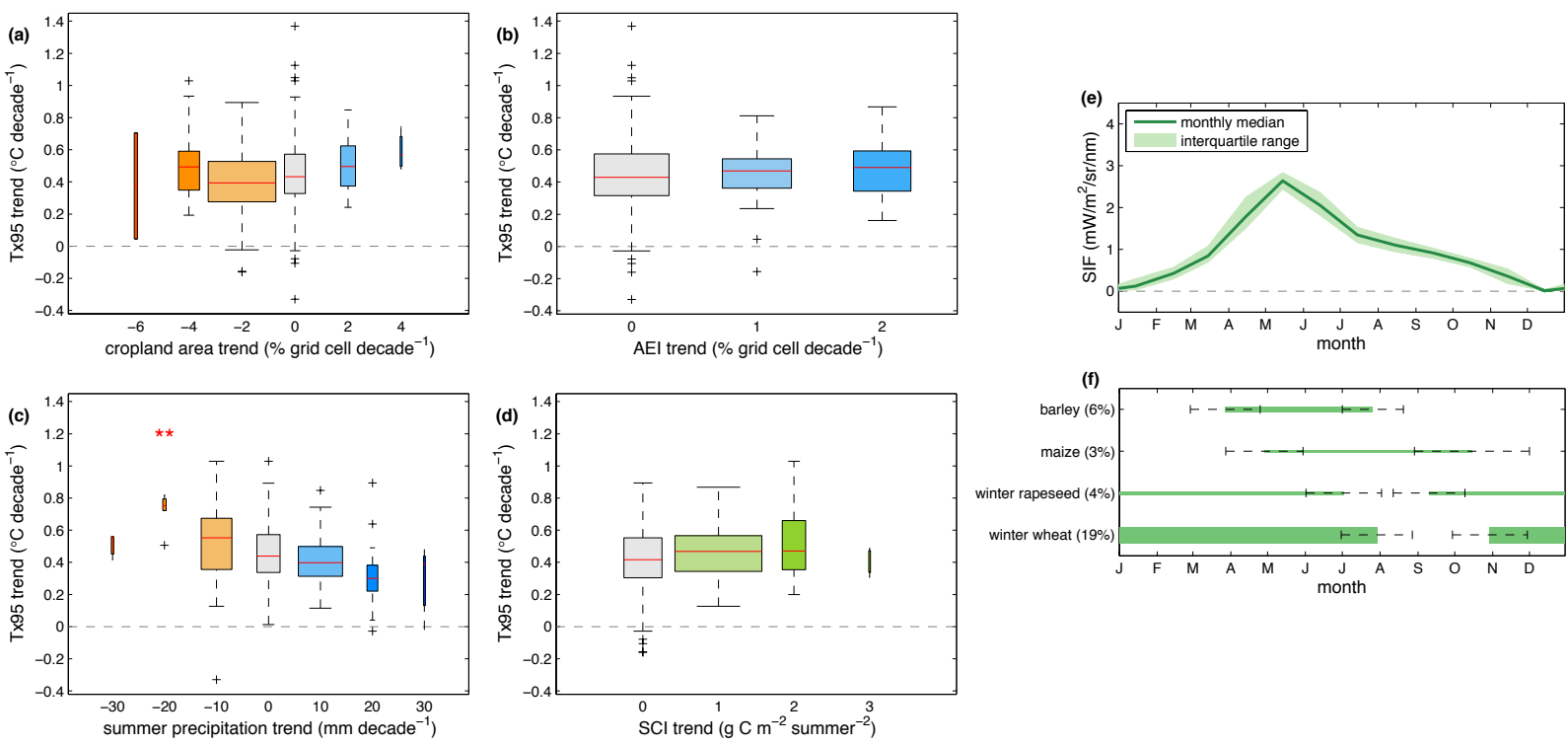

FIG. 10. Same as in Figures 6 and 7, but for Western Europe. Phenology is shown in (e) and (f) for the major crop production areas of Southern England and Northwest France. 

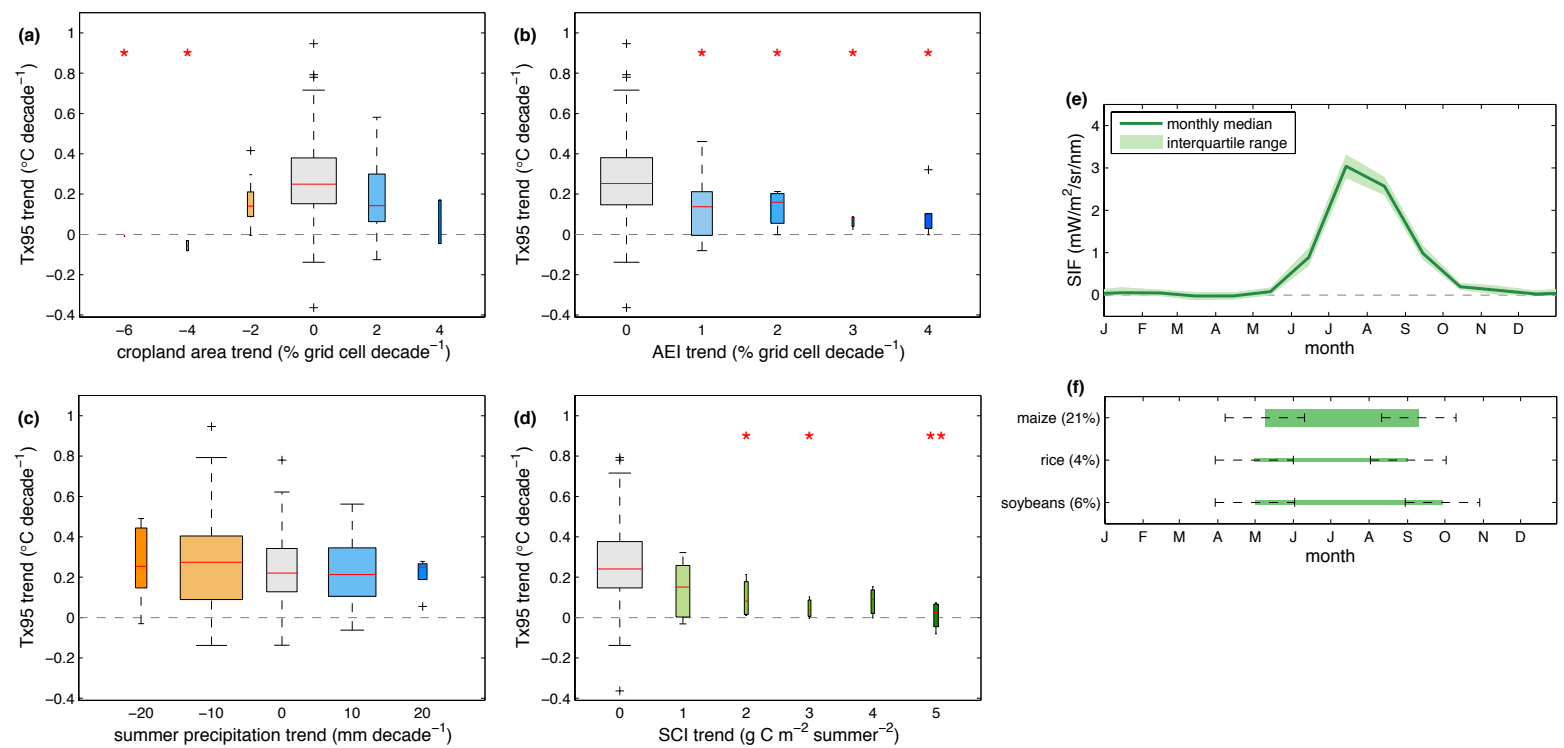

FIG. 11. Same as in Figures 6 and 7, but for Northern East Asia. Phenology is shown in (e) and (f) for the major crop production areas of Northeast China. 

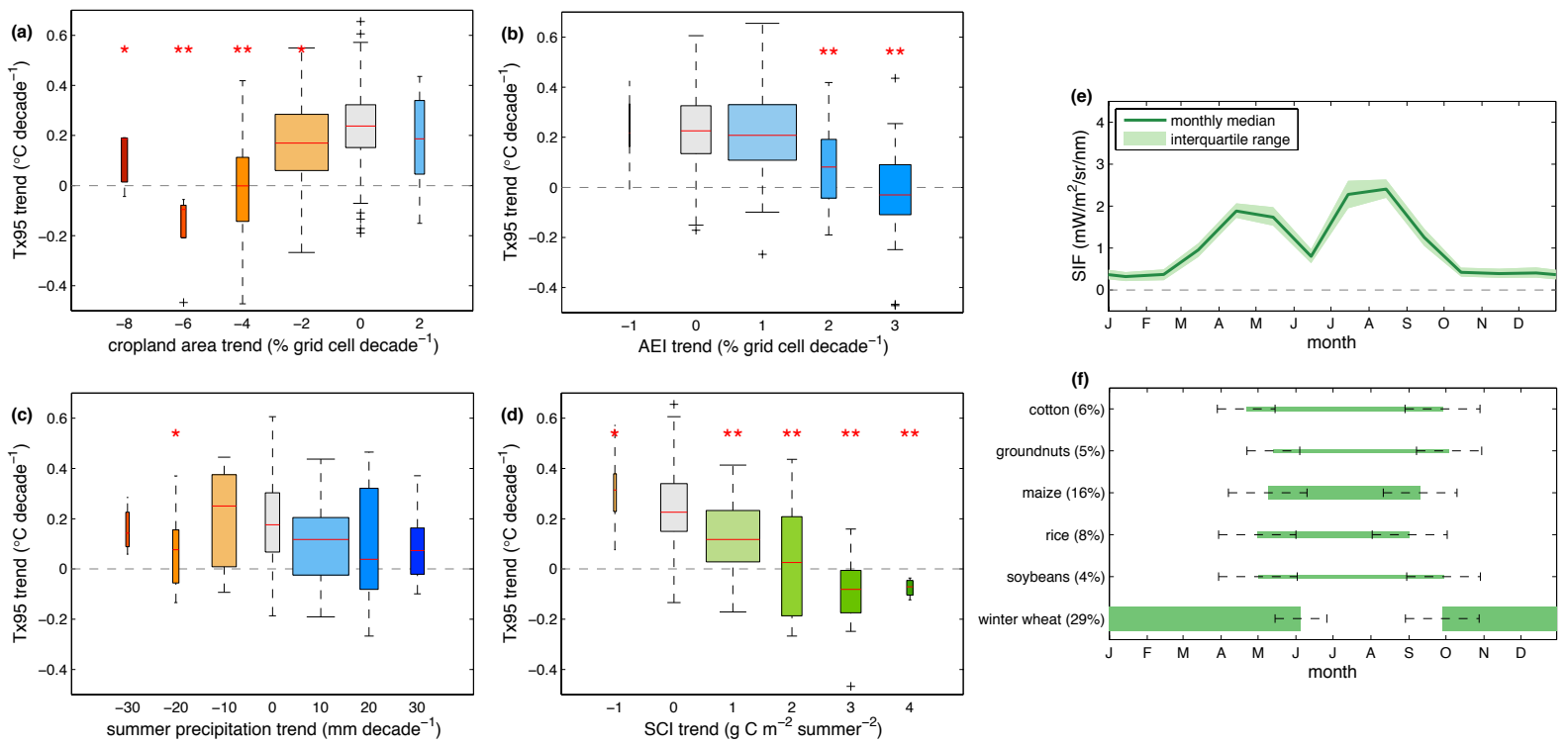

FIG. 12. Same as in Figures 6 and 7, but for Southern East Asia. Phenology is shown in (e) and (f) for the major crop production areas of the North China Plain. 

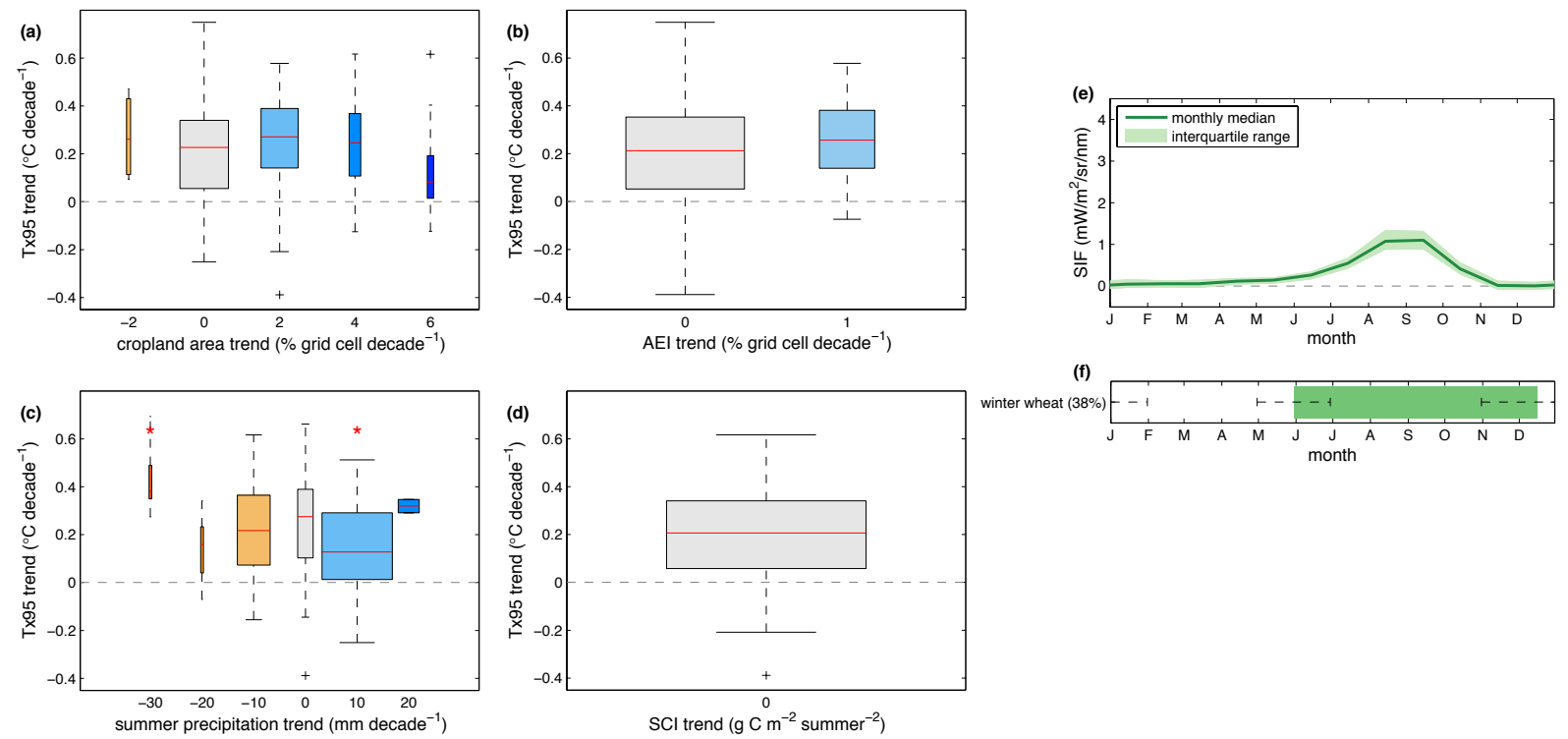

FIG. 13. Same as in Figures 6 and 7, but for Southern Australia. Phenology is shown in (e) and (f) for the major crop production areas of Western Australia. 

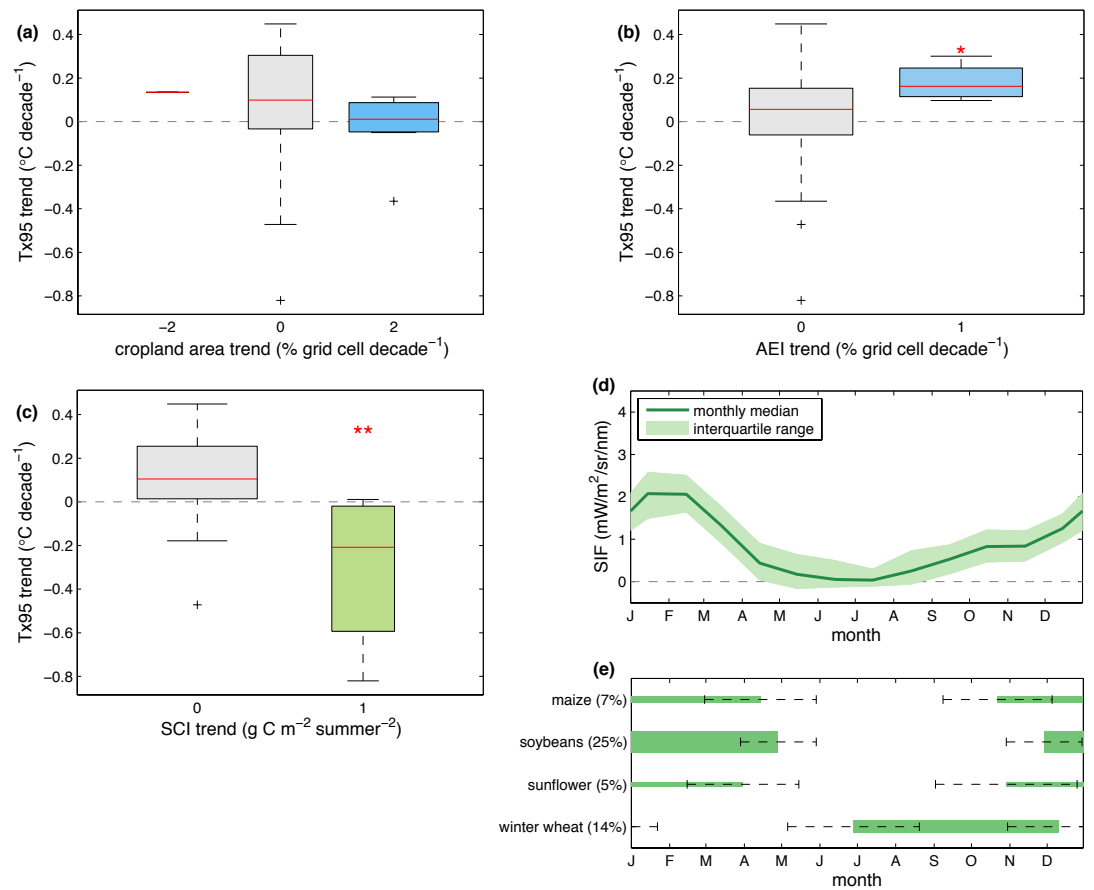

FIG. 14. Same as in Figures 6 and 7, but for Southern South America. Phenology is shown in (d) and (e) for the major crop production areas of the Argentine Pampas. 

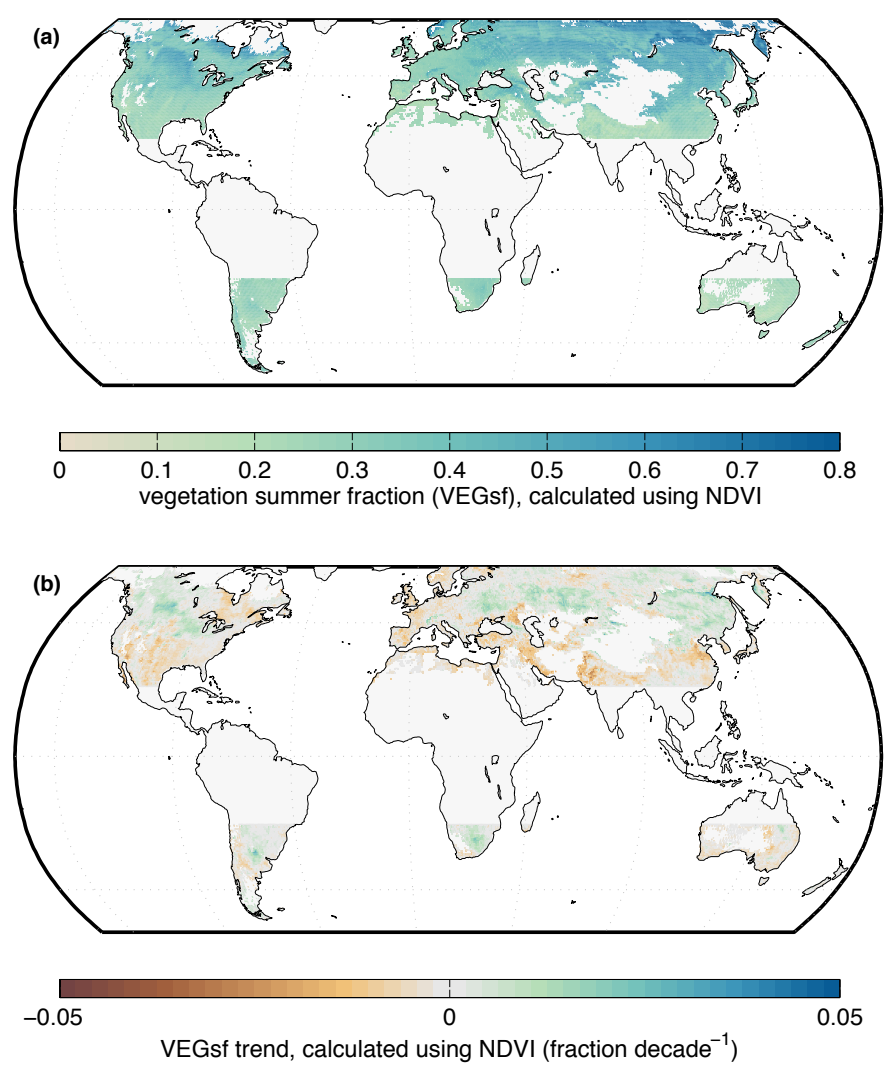

FIG. 15. (a) VEGsf calculated using the GIMMS NDVI data over the years 2007-2012, consistent with the calculation for SIF. (b) The decadal trend in VEGsf calculated using GIMMS NDVI data over the years 1982-2013. Areas where VEGsf was not calculated using the SIF data are masked. 

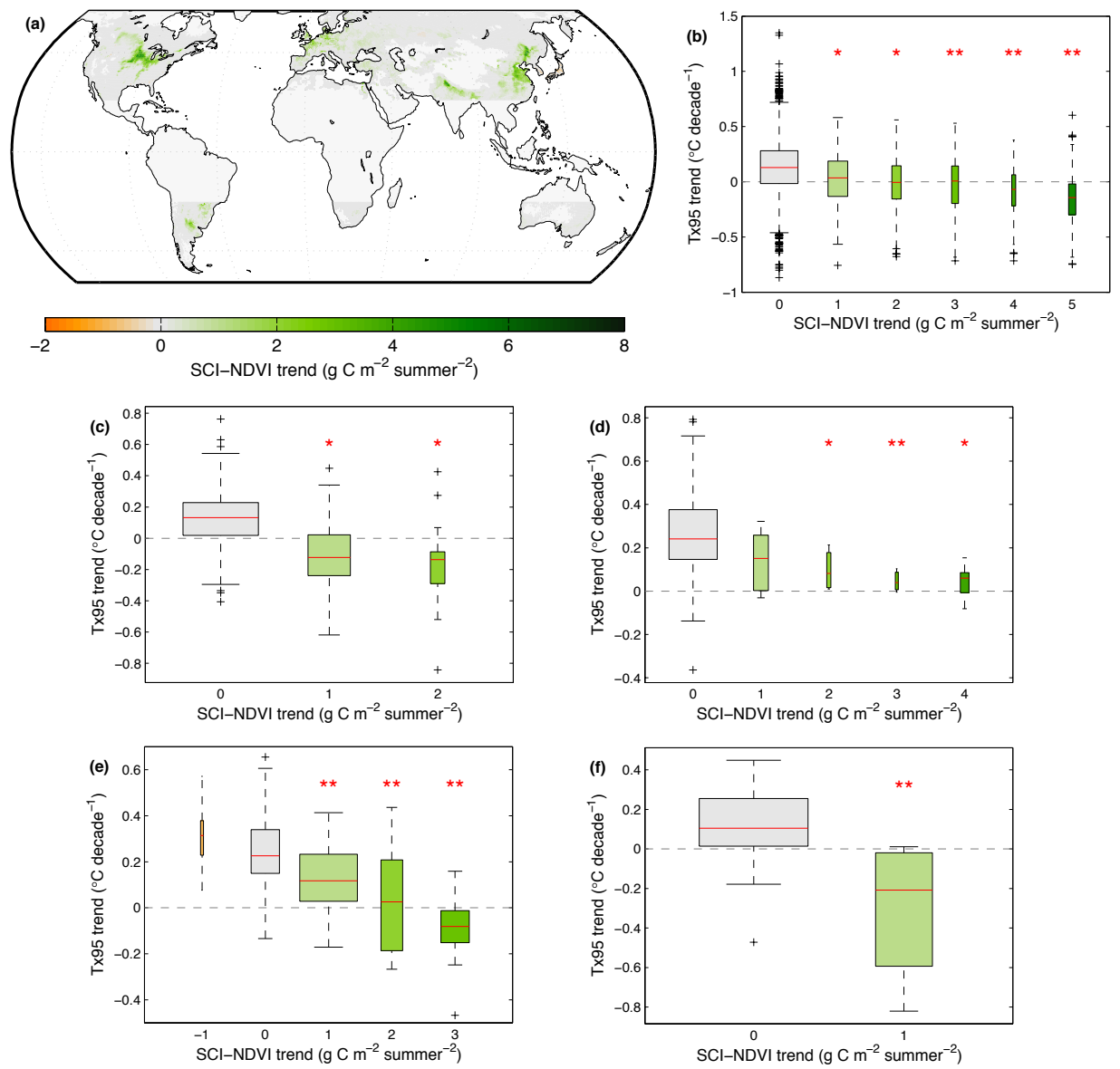

FIG. 16. (a) The summer cropping intensity index calculated using GIMMS NDVI data instead of SIF to calculate the vegetation summer fraction (SCI-NDVI). Associations between SCI-NDVI and $95^{\text {th }}$ percentile summer temperature trends for (b) Central North America, (c) Northern North America, (d) Northern East Asia, (e) Southern East Asia, (f) and Southern South America. 